\title{
MERCURY CALIBRATION SYSTEM
}

\section{TOPICAL REPORT}

Start Date: 2004

End Date: 2009

By

John F. Schabron

Eric W. Kalberer

Joseph F. Rovani

Mark M. Sanderson

Ryan B. Boysen

William C. Schuster

April 30, 2009

Work Performed Under Cooperative Agreement

Task 58 underDE-FC26-98FT40323

For

Thermo Fisher Scientific

Franklin, Massachusetts

And

U.S. Department of Energy

Office of Fossil Energy

National Energy Technology Laboratory

Morgantown, West Virginia

By

Western Research Institute

Laramie, Wyoming

Kamalendu Das

Task 58 


\section{TABLE OF CONTENTS}

Page

LIST OF TABLES AND FIGURES......................................................................... iii

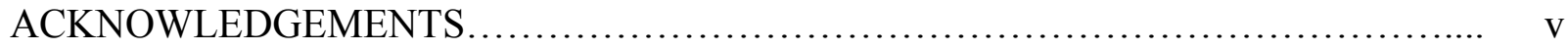

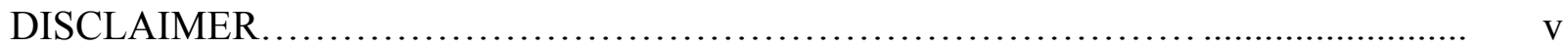

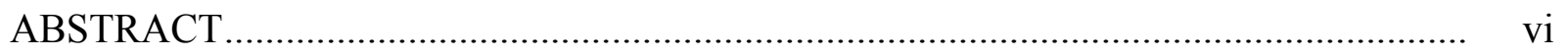

EXECUTIVE SUMMARY ...................................................... viii

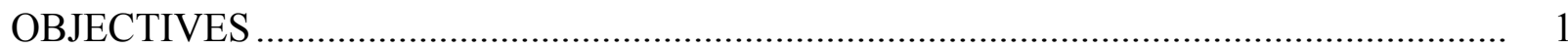

INTRODUCTION

EXPERIMENTAL

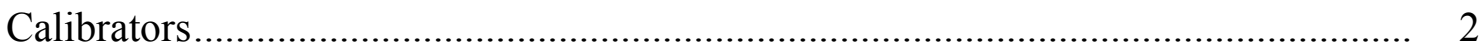

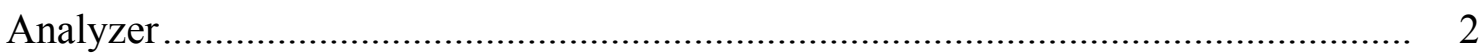

Compressed Air Source ................................................................................ 3

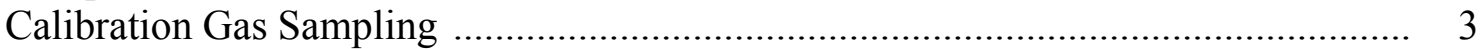

Stand-Alone Oxidizer Unit ...........................................................................

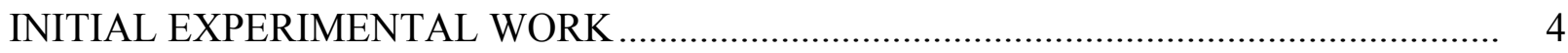

Nesting Analysis for Calibrator Comparison................................................................ 4

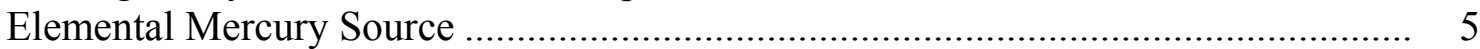

ELEMENTAL GENERATOR QUALIFICATION EXPERIMENTS ................................... 8

Calibrator Linearity Output Profiles ....................................................................... 9

Effect of Back Pressure on Calibrator Output ....................................................... 11

Effect of Line Voltage on Calibrator Output .......................................................... 14

Effect of Ambient Temperature on Calibrator Output.............................................. 18

Effect of Ambient Pressure on Calibrator Output......................................................... 21

OXIDIZED MERCURY GENERATOR CONVERSION EFFICIENCY ................................ 24

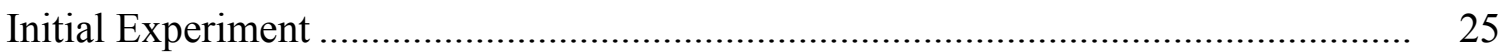

Quantitative Stand-Alone Oxidizer Procedure ........................................................ 28

WRI Conversion Efficiency Experiments .......................................................... 30

SAOX Efficiency Results ............................................................................... 34

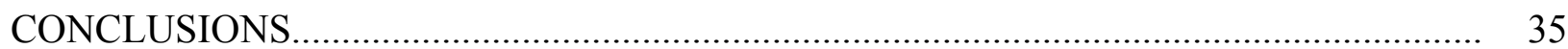

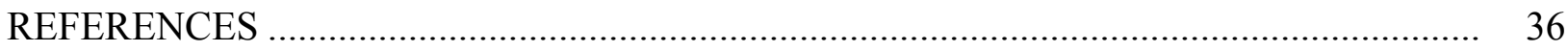




\section{LIST OF TABLES AND FIGURES}

Table

$\underline{\text { Page }}$

1. Calibrator Comparison Nesting Sequence ...................................................... 4

2. Nesting Data for Two Thermo 81i Calibrators Over a Sequential Five-Day Period and After Shipping to and from NIST (Day 6) and to and from Thermo Fisher (Day 7)

3. Response Data for Thermo 02 Calibrator 10

4. Response Data for Thermo 03 Calibrator 11

5. Back Pressure Data for Thermo 02 Calibrator Cal Gas Outlet 13

6. Back Pressure Data for Thermo 02 Calibrator Probe Port Outlet. 14

7. Line Voltage Variation Data for Thermo 02 Calibrator 16

8. Nested Line Voltage Variation Data for Thermo 02 Calibrator 17

9. Ambient Temperature Data for Thermo 02 Calibrator at $20^{\circ} \mathrm{C}$ and $30{ }^{\circ} \mathrm{C}$

10. Ambient Temperature Data for Thermo 02 Calibrator at $10{ }^{\circ} \mathrm{C}$

11. Recheck of Ambient Temperature Data for Thermo 02 Calibrator at $10{ }^{\circ} \mathrm{C}$. 20

12. Ambient Pressure Variation Data for Thermo 02 Calibrator at $5 \mu \mathrm{g} / \mathrm{m}^{3}$ 22

13. Ambient Pressure Variation Data for Thermo 02 Calibrator at $15 \mu \mathrm{g} / \mathrm{m}^{3}$ 23

14. Ambient Pressure Variation Data for Thermo 02 Calibrator at $30 \mu \mathrm{g} / \mathrm{m}^{3}$ 24

15. Elemental Mercury Measurements at Key Points of the Oxidizer Experiment 27 
1. Changes in Output Concentration After Two Shipping Events (Day 6, Day 7) at Concentrations Ranging From 5-50 ug/ $\mathrm{m}^{3}$

2. Linear Response Profile for Thermo 02 Calibrator ........................................... 10

3. Linear Response Profile for Thermo 03 Calibrator ............................................ 11

4. Back Pressure Experiment Valve.................................................................... 12

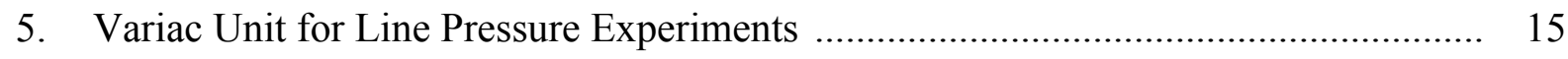

6. Drift in Thermo 80i Lamp Intensity............................................................. 17

7. Environmental Chamber for Ambient Temperature Experiments........................... 18

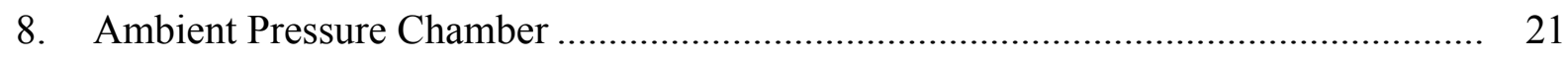

9. Thermo Fisher Stand-alone Oxidizer Unit.......................................................... 26

10. Schematic of the Experimental Setup for SAOX Testing ..................................... 30

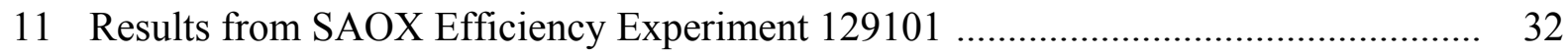

12 Results from SAOX Efficiency Experiment 129102 .......................................... 33

13 Results from SAOX Efficiency Experiment 129103 ......................................... 34 


\section{ACKNOWLEDGMENTS}

Funding for this study was provided by the U.S. Department of Energy under Cooperative Agreement DE-FC26-98FT40323, and by Thermo Fisher Scientific.

\section{DISCLAIMER}

This report was prepared as an account of work sponsored by an agency of the United States Government. Neither the United States Government nor any agencies thereof, nor any of its employees, makes any warranty, expressed or implied, or assumes any legal liability or responsibility for the accuracy, completeness, or usefulness of any information, apparatus, product, or process disclosed, or represents that its use would not infringe on privately owned rights. Reference herein to any specific commercial product, process, or service by trade name, trademark, manufacturer, or otherwise does not necessarily constitute or imply its endorsement, recommendation, or favoring by the United States Government or any agency thereof. The views and opinions of authors expressed herein do not necessarily state or reflect those of the United States Government or any agency thereof. 


\begin{abstract}
U.S. Environmental Protection Agency (EPA) Performance Specification 12 in the Clean Air Mercury Rule (CAMR) states that a mercury CEM must be calibrated with National Institute for Standards and Technology (NIST) -traceable standards. In early 2009, a NIST traceable standard for elemental mercury CEM calibration still does not exist. Despite the vacature of CAMR by a Federal appeals court in early 2008, a NIST traceable standard is still needed for whatever regulation is implemented in the future. Thermo Fisher is a major vendor providing complete integrated mercury continuous emissions monitoring (CEM) systems to the industry. WRI is participating with EPA, EPRI, NIST, and Thermo Fisher towards the development of the criteria that will be used in the traceability protocols to be issued by EPA. An initial draft of an elemental mercury calibration traceability protocol was distributed for comment to the participating research groups and vendors on a limited basis in early May 2007. In August 2007, EPA issued an interim traceability protocol for elemental mercury calibrators. Various working drafts of the new interim traceability protocols were distributed in late 2008 and early 2009 to participants in the Mercury Standards Working Committee project. The protocols include sections on qualification and certification. The qualification section describes in general terms tests that must be conducted by the calibrator vendors to demonstrate that their calibration equipment meets the minimum requirements to be established by EPA for use in CAMR monitoring. Variables to be examined include linearity, ambient temperature, back pressure, ambient pressure, line voltage, and effects of shipping. None of the procedures were described in detail in the draft interim documents; however they describe what EPA would like to eventually develop. WRI is providing the data and results to EPA for use in developing revised experimental procedures and realistic acceptance criteria based on actual capabilities of the current calibration technology. As part of the current effort, WRI worked with Thermo Fisher elemental mercury calibrator units to conduct qualification experiments to demonstrate their performance characteristics under a variety of conditions and to demonstrate that they qualify for use in the CEM calibration program.
\end{abstract}

Monitoring of speciated mercury is another concern of this research. The mercury emissions from coal-fired power plants are comprised of both elemental and oxidized mercury. Current CEM analyzers are designed to measure elemental mercury only. Oxidized mercury must first be converted to elemental mercury prior to entering the analyzer inlet in order to be measured. CEM systems must demonstrate the ability to measure both elemental and oxidized mercury. This requires the use of oxidized mercury generators with an efficient conversion of the oxidized mercury to elemental mercury. There are currently two basic types of mercuric chloride $\left(\mathrm{HgCl}_{2}\right)$ generators used for this purpose. One is an evaporative $\mathrm{HgCl}_{2}$ generator, which produces gas standards of known concentration by vaporization of aqueous $\mathrm{HgCl}_{2}$ solutions and quantitative mixing with a diluent carrier gas. The other is a device that converts the output from an elemental $\mathrm{Hg}$ generator to $\mathrm{HgCl}_{2}$ by means of a chemical reaction with chlorine gas. The 
Thermo Fisher oxidizer system involves reaction of elemental mercury vapor with chlorine gas at an elevated temperature.

The draft interim protocol for oxidized mercury units involving reaction with chlorine gas requires the vendors to demonstrate high efficiency of oxidation of an elemental mercury stream from an elemental mercury vapor generator. The Thermo Fisher oxidizer unit is designed to operate at the power plant stack at the probe outlet. Following oxidation of elemental mercury from reaction with chlorine gas, a high temperature module reduces the mercuric chloride back to elemental mercury. WRI conducted work with a custom laboratory configured stand-alone oxidized mercury generator unit provided by Thermo Fisher to perform experiments to demonstrate the high efficiency of oxidation on reaction with chlorine gas, and reduction back to elemental mercury. 


\section{EXECUTIVE SUMMARY}

U.S. Environmental Protection Agency (EPA) Performance Specification 12 in the Clean Air Mercury Rule (CAMR) states that a mercury CEM must be calibrated with National Institute for Standards and Technology (NIST) -traceable standards. In early 2009, a NIST traceable standard for elemental mercury CEM calibration still does not exist. Despite the vacature of CAMR by a Federal appeals court in early 2008, a NIST traceable standard is still needed for whatever regulation is implemented in the future. Thermo Fisher is a major vendor providing complete integrated mercury continuous emissions monitoring (CEM) systems to the industry. WRI is participating with EPA, EPRI, NIST, and Thermo Fisher towards the development of the criteria that will be used in the traceability protocols to be issued by EPA. An initial draft of an elemental mercury calibration traceability protocol was distributed for comment to the participating research groups and vendors on a limited basis in early May 2007. In August 2007, EPA issued an interim traceability protocol for elemental mercury calibrators. Various working drafts of the new interim traceability protocols were distributed in late 2008 and early 2009 to participants in the Mercury Standards Working Committee project. The protocols include sections on qualification and certification. The qualification section describes in general terms tests that must be conducted by the calibrator vendors to demonstrate that their calibration equipment meets the minimum requirements to be established by EPA for use in CAMR monitoring. Variables to be examined include linearity, ambient temperature, back pressure, ambient pressure, line voltage, and effects of shipping. None of the procedures were described in detail in the draft interim documents; however they describe what EPA would like to eventually develop. WRI is providing the data and results to EPA for use in developing revised experimental procedures and realistic acceptance criteria based on actual capabilities of the current calibration technology. As part of the current effort, WRI worked with Thermo Fisher elemental mercury calibrator units to conduct qualification experiments to demonstrate their performance characteristics under a variety of conditions and to demonstrate that they qualify for use in the CEM calibration program.

Monitoring of speciated mercury is another concern of this research. The mercury emissions from coal-fired power plants are comprised of both elemental and oxidized mercury. Current CEM analyzers are designed to measure elemental mercury only. Oxidized mercury must first be converted to elemental mercury prior to entering the analyzer inlet in order to be measured. CEM systems must demonstrate the ability to measure both elemental and oxidized mercury. This requires the use of oxidized mercury generators with an efficient conversion of the oxidized mercury to elemental mercury. There are currently two basic types of mercuric chloride $\left(\mathrm{HgCl}_{2}\right)$ generators used for this purpose. One is an evaporative $\mathrm{HgCl}_{2}$ generator, which produces gas standards of known concentration by vaporization of aqueous $\mathrm{HgCl}_{2}$ solutions and quantitative mixing with a diluent carrier gas. The other is a device that converts the output from an elemental $\mathrm{Hg}$ generator to $\mathrm{HgCl}_{2}$ by means of a chemical reaction with chlorine gas. The 
Thermo Fisher oxidizer system involves reaction of elemental mercury vapor with chlorine gas at an elevated temperature.

The draft interim protocol for oxidized mercury units involving reaction with chlorine gas requires the vendors to demonstrate high efficiency of oxidation of an elemental mercury stream from an elemental mercury vapor generator. The Thermo Fisher oxidizer unit is designed to operate at the power plant stack at the probe outlet. Following oxidation of elemental mercury from reaction with chlorine gas, a high temperature module reduces the mercuric chloride back to elemental mercury. WRI conducted work with a custom laboratory configured stand-alone oxidized mercury generator unit provided by Thermo Fisher to perform experiments to demonstrate the high efficiency of oxidation on reaction with chlorine gas, and reduction back to elemental mercury. 


\section{OBJECTIVES}

The overall objectives of this task include: evaluation of prototype calibration devices available from Thermo Fisher; identification of key parameters; and definition of the necessary elements of successful design and operation. Another important aspect for the co-sponsor, Thermo Fisher is that the Environmental Protection Agency (EPA) has indicated that the work that WRI is doing with the Thermo calibrators will result in advancing the knowledge of the technology towards the goal of satisfying the Qualification requirements for CEM calibration units.

\section{INTRODUCTION}

More than 800 stacks from coal fired power plants will be affected by new mercury emissions rules. The specific rule that will emerge is unknown at this time, since the Clean Air Mercury Rule (CAMR) was vacated by a Federal appeals court in early 2008. Whatever changes occur in mercury control requirements in the future, NIST traceable calibration standards will be required for continuous emissions monitoring (CEM).

Western Research Institute (WRI) has conducted work with input from Thermo Fisher Scientific under JSR Task 58 to evaluate Thermo Fisher elemental and oxidized mercury vapor calibration units to assist in optimizing CEM system capabilities and procedures for accurate mercury monitoring. CAMR requires that calibration be performed with NIST-traceable standards (Federal Register 2005). In a closely related effort, WRI also worked under the related JSR Task 62 with the Electric Power Research Institute (EPRI), to participate in the Mercury Standards Working Committee effort and assist the National Institute of Standards and Technology (NIST), and the Environmental Protection Agency (EPA) by developing test methodology and generating data with calibrators from several vendors, and recommending procedures to inform the regulatory process for the NIST traceability protocol to be provided by EPA. EPA has issued draft input documents for review of the traceability protocol in late 2008 and early 2009 in anticipation of the next interim protocol. The next interim traceability protocol document is expected to issue in 2009.

In August 2007, EPA issued a conceptual interim traceability protocol for elemental mercury calibrators (EPA 2007). The document is divided into two separate sections, Qualification and Certification. The Qualification Section describes in general terms tests that must be conducted by the calibrator vendors to demonstrate that their calibration equipment meets the minimum requirements to be established by EPA for use in CAMR monitoring. Variables to be examined include linearity, ambient temperature, back pressure, ambient pressure, line voltage, and effects of shipping. None of the procedures were described in the 2007 interim document, since it was an initial draft of what EPA would like to eventually 
develop. Under JSR Task 62, WRI developed and demonstrated a series of proposed qualification procedures for elemental mercury calibrators. WRI has provided input to EPA for use in developing experimental procedures and realistic acceptance criteria based on actual capabilities of the current calibration technology. The Certification Section of the Interim Protocol deals with the experimental criteria required to certify a calibrator unit as NIST traceable, and the procedures verifying calibrator output over time at a power plant site.

As part of the current effort, WRI has worked with Thermo Fisher elemental mercury calibrator units to conduct qualification experiments to demonstrate their performance characteristics under a variety of conditions and to help demonstrate that they qualify for use in the CEM calibration program.

The draft 2008 and 2009 interim protocols require that the efficiency of oxidation and subsequent reduction of mercury for oxidized mercury generator units involving reaction with chlorine gas be demonstrated. The Thermo Fisher oxidizer unit is designed to operate at the power plant stack at the probe outlet. WRI worked with a custom laboratory configured standalone oxidized mercury generator unit provided by Thermo Fisher to conduct experiments to demonstrate the efficiency of oxidation on reaction with chlorine gas, and the subsequent reduction to elemental mercury.

\section{EXPERIMENTAL}

\section{$\underline{\text { Calibrators }}$}

Model $81 \mathrm{i}$ elemental calibrator units were provided by Thermo Fisher. These were designated Thermo 02, Thermo 03, and Thermo 04. Operating instructions from Thermo Fisher were followed for the use of each of these devices. Thermo 02 Serial Number 0613917136 was originally delivered to NIST in August 2006 and received at WRI in January 2007. Thermo 03 Serial Number 0636220561 was delivered to WRI in February 2007. Thermo 04 (serial \# 0618117699) was provided to WRI in late 2008. The $81 \mathrm{i}$ elemental mercury calibrators are constant vppb devices. The diluent air flow is automatically adjusted to maintain a constant mass flow of air. The actual vppb corresponds to user specific concentration in $\mu \mathrm{g} / \mathrm{m}^{3}$ at standard reference conditions defined by EPA of $1.0 \mathrm{~atm}$ and $20^{\circ} \mathrm{C}$. The actual $\mu \mathrm{g} / \mathrm{m}^{3}$ output from the calibrator changes as a function of back pressure and altitude.

\section{$\underline{\text { Analyzer }}$}

A Thermo Fisher Model 80i continuous emission atomic fluorescence elemental mercury analyzer was provided by Thermo Fisher. Model 80i Mercury Analyzer Serial Number 
0636220551 was delivered to WRI in February 2007. A vacuum pump at the exit port of the 80i analyzer cell draws sample through the inlet port of the optical cell. The optical cell is maintained at a constant temperature of $45^{\circ} \mathrm{C}$. The constant vppb vapor stream from the calibrator does not change with back pressure or altitude for the $80 \mathrm{i}$ analyzer, since the internal optical chamber is maintained at a constant specific vacuum pressure near $40 \mathrm{~mm} \mathrm{Hg}$ throughout a series of calibration and sample measurements. The analyzer actually measures a vppb concentration in the optical cell and automatically converts this to a $\mu \mathrm{g} / \mathrm{m}^{3}$ concentration at standard conditions defined by EPA as 1.0 atm and $20^{\circ} \mathrm{C}$. The analyzer was not recalibrated from its factory settings prior to the start of the experiments described in this report. The analyzer was updated in April 2007 with the new Thermo iPort32 software with a Thermo lamp heater upgrade kit. Responses were recorded using a 60 second averaging time.

\section{Compressed Air Source}

For the initial nesting work, breathing air quality cylinders were used as the compressed air source. These were equipped with Matheson 13x molecular sieve cartridges with 12 micron filters to remove oil, water, and particulates. For the qualification work, a Thomas T-2820ST portable oil-free air compressor with an indicating silica gel desiccant cartridge and 5-micron filter was used. The effect of the two sources, cylinder vs. compressor on manifold pressure and concentration has been evaluated experimentally using a Thermo Fisher $81 \mathrm{i}$ calibrator and found to be insignificant. There was no background mercury vapor from either air source. In late 2008 prior to the quantitative stand-alone oxidizer experiments, additional carbon cleanup cartridges provided by Thermo Fisher were added to the compressed air lines in the laboratory near to the inlets of the Reference and Candidate calibrators. As a further precaution against any potential contamination of air from the room air used by the compressors or the compressed air exiting the compressors, Tekran air purification manifolds were installed at each air compressor. Each contains air dryi9ng cartridges, particulate filters, and iodated carbon scrubbers to ensure that there is no mercury in the air. For future work, we plan to use either nitrogen gas from liquid nitrogen dewars, or a new purification train to provide ISO 8573.1 Class 1 dirt (0.1 micron), Class 2 water $\left(-40^{\circ} \mathrm{C}\right.$ dew point $)$, Class 1 oil $\left(0.01 . \mathrm{mg} / \mathrm{m}^{3}\right)$ specification air quality.

\section{Calibration Gas Sampling}

A PFA "Tee" connector with compression fittings for $1 / 4$-inch outside diameter (O.D.) PFA tubing was employed as the initial design vapor introduction device for the $80 \mathrm{i}$ analyzer for the initial side by side nesting studies. The three ports of the Tee were connected to the Cal Gas outlet of the calibrator, the inlet port of the analyzer, and a vent line into to an open negative pressure vent pipe arrangement via 6 feet of $1 / 4$-inch O.D. PFA tubing. Although this style of inlet has minimal void volume in the delivery of mercury vapor to the analyzer, there was some 
concern that the 6 feet length of vent tubing could cause some back pressure at the analyzer inlet. For the initial nesting studies comparing two identical model numbers, this was not problematic since tubing lengths and flow rates were identical for both calibrators. For subsequent studies, a 3/8-inch Tee was used at the analyzer inlet to minimize line pressure effects.

\section{$\underline{\text { Stand-Alone Oxidizer Unit }}$}

A custom built Stand Alone Oxidation (SAOX) unit was provided for this project by Thermo Fisher. The chlorine gas used for the oxidation reaction was $900 \mathrm{ppm}$ chlorine in nitrogen obtained from Airgas. The unit has two heated chambers. The oxidation chamber is heated to $400{ }^{\circ} \mathrm{C}$. The reduction chamber was maintained at $760{ }^{\circ} \mathrm{C}$. Inlet elemental mercury calibration gas was from a Thermo $81 \mathrm{i}$ elemental mercury calibrator.

\section{INITIAL EXPERIMENTAL WORK}

\section{Nesting Analysis for Calibrator Comparison}

Responses from the 80i analyzer were obtained in 8 minute intervals for each reading. This included 3 minutes analyzer equilibration time prior to 5 minutes of data collection. When the mercury concentration was changed at the $81 \mathrm{i}$ calibrator, a minimum of 10 minutes equilibration time was determined to be adequate prior to the next measurement. Zero backgrounds at the analyzer were recorded at the beginning and end of each measurement sequence to document any zero drift. The $80 \mathrm{i}$ output readings are 5-minute averages. A typical nesting ratio procedure sequence is provided in Table 1 below.

Table 1. Calibrator Comparison Nesting Sequence

\begin{tabular}{|l|l|}
\hline Calibrator Unit & Reading \\
\hline Zero Air & 0 \\
\hline Reference Calibrator A & $\mathrm{A}_{1}$ \\
\hline Candidate Calibrator B & $\mathrm{B}_{1}$ \\
\hline Reference Calibrator A & $\mathrm{A}_{2}$ \\
\hline Candidate Calibrator B & $\mathrm{B}_{2}$ \\
\hline Reference Calibrator A & $\mathrm{A}_{3}$ \\
\hline Candidate Calibrator B & $\mathrm{B}_{3}$ \\
\hline Reference Calibrator A & $\mathrm{A}_{4}$ \\
\hline Zero Air & 0 \\
\hline
\end{tabular}


A nested ratio for a sequence $A_{1}-B_{1}-A_{2}$ for $81 \mathrm{i}$ calibrators $A$ (Reference) and $B$ (Candidate), for example is calculated by dividing the analyzer reading $\mathrm{B}_{1}$ by the mean value of analyzer readings $A_{1}$ and $A_{2}$, for example. For a series of three nested ratios, the three relative outputs are calculated as shown below.

$$
\begin{aligned}
& \text { Ratio 1 }=\left(\mathrm{A}_{1}+\mathrm{A}_{2}\right) / \mathrm{B}_{1} \\
& \text { Ratio 2 }=\left(\mathrm{A}_{2}+\mathrm{A}_{3}\right) / \mathrm{B}_{2} \\
& \text { Ratio } 1=\left(\mathrm{A}_{3}+\mathrm{A}_{4}\right) / \mathrm{B}_{3}
\end{aligned}
$$

The mean nested ratio $R_{M}$ is calculated as (Ratio $1+$ Ratio $2+$ Ratio 3) / 3

Nesting data for a series of measurements comparing Thermo 02 and Thermo 03 outputs at four concentrations of $5,15,30$, and $50 \mu \mathrm{g} / \mathrm{m}^{3}$ over 5 days using the $80 \mathrm{i}$ spectrometer are provided in Table 2. The results for the first five days show that the nested ratios did not change significantly for any of the concentrations studied.

\section{Elemental Mercury Source}

A significant problem with the nesting ratios was observed at NIST when Thermo 02 was shipped to NIST in Gaithersburg, MD from WRI in Laramie, WY in late 2007. Upon receipt of the unit, NIST noted that the output was significantly below the expected values, especially at high concentrations. They shipped it back to WRI. Following receipt of the unit, the output of Thermo 02 at $30 \mu \mathrm{g} / \mathrm{m}^{3}$ was confirmed to be about $17 \%$ lower relative to Thermo 03 prior to shipping and nearly $30 \%$ lower than Thermo 03 at $50 \mu \mathrm{g} / \mathrm{m}^{3}$ (Figure 1). It appears likely that sufficient elemental mercury vapor was not being produced from the elemental mercury source equilibrium chamber. Thermo 02 was one of the original two Thermo calibrators (Thermo 01, Thermo 02) used at NIST by Bill Dorko and Joe Rovani in late 2006 to develop the nesting procedure (Schabron et al. 2007). For the initial calibrator work, the source gas at NIST had been a direct connection to house air of unknown quality. In retrospect, it appears possible that the sudden drop-off in concentration from the original Thermo 01 prototype unit at NIST in September 2006 could also have been due to elemental mercury source passivation. The air supply used at WRI for all of this initial work was breathing quality compressed air cylinders equipped with Matheson 13x molecular sieve purifier cartridges and a 12-micron filter designed to remove any oil, water, or particulates. PFA tubing was used to connect the air cylinders to the calibrator supply inlets. The Thermo 02 unit was subsequently shipped to Thermo Fisher for evaluation in late 2007. Thermo Fisher did not see a significant deviation from expected values. They shipped the unit back to WRI in Laramie. The nesting procedure was repeated at WRI, and it was apparent that the nesting ratios had been restored to be near, but not identical values relative to Thermo 03 (Table 2, Figure 1). The exact cause of this was never determined. One possible explanation is that a transient air channel could have formed in the fine powder molecular sieve bed containing the elemental mercury in the equilibrium chamber as a result of 
the mechanical shocks and jarring of commercial shipping. Another possible explanation is contamination of the surface of the elemental mercury had occurred, and fresh elemental mercury was exposed during movement, restoring function. The bed could have rearranged itself during the trip to Thermo Fisher and the final return trip to WRI.

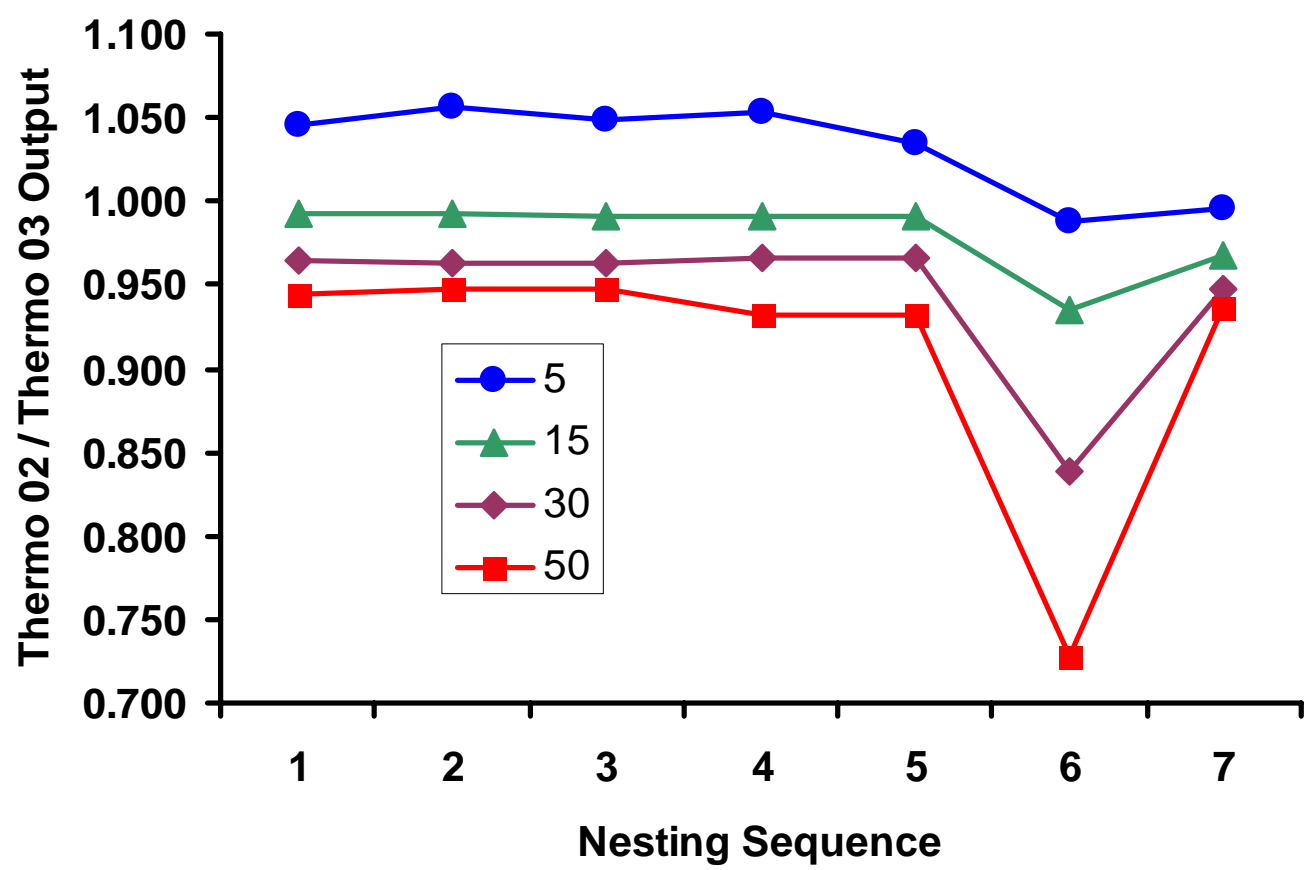

Figure 1. Changes in Thermo 02 Output Relative to Thermo 03 After Two Shipping Events (Day 6, Day 7) at Concentrations Ranging From 5-50 $\mu \mathrm{g} / \mathrm{m}^{3}$.

It is evident in Figure 1 that the effect is more pronounced at high concentrations than at lower concentrations. This phenomenon is independent of the various vendor units with which we have worked over the last several years. This observation is the basis of a new ratio QC check procedure that we developed for elemental calibrators. EPA has subsequently incorporated it into the 2009 elemental mercury calibrator interim traceability protocols as Section 7.2.2 for the mandatory QC check of reference generators.

In late 2007 the air source at WRI was switched from breathing quality air cylinders to an oil free air compressor recommended by Jeff Ryan at EPA, with an indicating silica gel desiccant cartridge and 5-micron filter. Apparent source passivation still occurred over time for various calibrator units. Operation was restored for two Thermo units for several months by adding about $0.3 \mathrm{~mL}$ pure elemental mercury to the source tubes. 
Table 2. Nesting Data for Two Thermo 81i Calibrators Over a Sequential Five-Day Period and After Shipping to and from NIST (Day 6) and to and from Thermo Fisher (Day 7).

\begin{tabular}{|c|c|c|c|c|c|c|c|c|c|c|c|c|c|c|c|c|c|c|c|c|}
\hline \multirow{2}{*}{\multicolumn{2}{|c|}{ Day 1}} & \multirow{3}{*}{$4 / 30 / 07$} & \multicolumn{3}{|l|}{\begin{tabular}{|l|} 
Day 2 \\
\end{tabular}} & \multicolumn{3}{|l|}{ Day 3} & \multirow{2}{*}{\multicolumn{3}{|c|}{ Day 4}} & \multirow{2}{*}{\multicolumn{2}{|c|}{ Day 5}} & \multirow{3}{*}{$5 / 3 / 07$} & \multicolumn{3}{|c|}{ After Shipping to/from } & \multicolumn{3}{|c|}{ After Shipping to/from } \\
\hline & & & & & $5 / 1 / 07$ & & & $5 / 2 / 07$ & & & & & & & NIST & & 8/29/07 & \multicolumn{2}{|c|}{ Thermo Fisher } & \multirow[t]{2}{*}{ 9/28/07 } \\
\hline $81 i$ Set & 80i Read & & $81 i \mathrm{Set}$ & 80i Read & & $81 i$ Set & Oi Read & & $81 i$ Set & 80i Read & & $81 i$ Set & 80i Read & & $81 i$ Set & 80i Read & & $81 i$ Set & 80i Read & \\
\hline Zero & 0.00 & Nesting & Zero & 0.00 & Nested & Zero & 0.00 & Nested & Zero & 0.00 & Nested & Zero & 0.00 & Nested & Zero & 0.00 & Nested & Zero & 0.00 & Nested \\
\hline $5 \mu \mathrm{g} / \mathrm{m}^{3}$ & $\underline{\mathrm{Hg}^{\circ} \mu \mathrm{g} / \mathrm{m}^{3}}$ & Ratio & $5 \mu \mathrm{g} / \mathrm{m}^{3}$ & $\mathrm{Hg}^{0} \mu \mathrm{g} / \mathrm{m}^{3}$ & Ratio & $5 \mu \mathrm{g} / \mathrm{m}^{3}$ & $\underline{\mathrm{Hg}^{0}} \mu \mathrm{g} / \mathrm{m}^{3}$ & Ratio & $5 \mu \mathrm{g} / \mathrm{m}^{3}$ & $\mu \mathrm{g} / \mathrm{m}^{3}$ & Ratio & $5 \mu \mathrm{g} / \mathrm{m}^{3}$ & $\mu \mathrm{g} / \mathrm{m}^{3}$ & Ratio & $5 \mu \mathrm{g} / \mathrm{m}^{3}$ & $\mu \mathrm{g} / \mathrm{m}^{3}$ & Ratio & $5 \mu \mathrm{g} / \mathrm{m}^{3}$ & $\mu \mathrm{g} / \mathrm{m}^{3}$ & Ratio \\
\hline Thermo02 & 4.90 & & Thermo 02 & 4.65 & & Thermo02 & 4.87 & & Thermo02 & 5.05 & & Thermo02 & 5.28 & & Thermo 02 & 5.65 & & Thermo02 & 5.70 & \\
\hline Thermo03 & 4.70 & 0.959 & Thermo03 & 4.41 & 0.948 & Thermo03 & 4.62 & 0.954 & Thermo03 & 4.79 & 0.951 & Thermo03 & 5.12 & 0.971 & Thermo03 & 5.75 & 1.016 & Thermo03 & 5.76 & 1.011 \\
\hline Thermo02 & 4.90 & & Thermo02 & 4.64 & & Thermo02 & 4.83 & & Thermo02 & 5.02 & & Thermo02 & 5.27 & & Thermo02 & 5.66 & & Thermo02 & 5.69 & \\
\hline Thermo03 & 4.68 & 0.955 & Thermo03 & 4.40 & 0.947 & Thermo03 & 4.61 & 0.955 & Thermo03 & 4.77 & 0.950 & Thermo03 & 5.08 & 0.963 & Thermo03 & 5.71 & 1.011 & Thermo03 & 5.71 & 1.004 \\
\hline Thermo02 & 4.91 & & Thermo02 & 4.64 & & Thermo02 & 4.83 & & Thermo02 & 5.01 & & Thermo02 & 5.27 & & hermo02 & 5.65 & & Thermo02 & 5.69 & \\
\hline Thermo03 & 4 & 0.954 & Thermo03 & 4. & 0.944 & Thermo03 & 4. & 0.954 & Thermo03 & 4.76 & 0.950 & Thermo03 & 5.08 & 0.963 & hermo03 & 5.70 & 1.009 & 03 & 5.68 & 1.001 \\
\hline Thermo02 & 4.90 & & Thermo02 & 4.61 & & Thermo02 & 4.81 & & Thermo02 & 5.00 & & Thermo02 & 5.27 & & Thermo02 & 5.64 & & Thermo02 & 5.67 & \\
\hline $15 \mu \mathrm{g} / \mathrm{m}^{3}$ & & & $15 \mu \mathrm{g} / \mathrm{m}^{3}$ & & & $15 \mu \mathrm{g} / \mathrm{m}^{3}$ & & & $15 \mu \mathrm{g} / \mathrm{m}^{3}$ & & & $15 \mu \mathrm{g} / \mathrm{m}^{3}$ & & & $15 \mu \mathrm{g} / \mathrm{m}^{3}$ & & & $5 \mu \mathrm{g} / \mathrm{m}^{3}$ & & \\
\hline Thermo02 & 14.56 & & $\overline{\text { Thermo02 }}$ & 13.66 & & $\overline{\text { Thermo02 }}$ & 14.22 & & Thermo02 & 14.81 & & $\overline{\text { Thermo02 }}$ & 15.54 & & $\overline{\text { Thermo } 02}$ & 15.87 & & Thermo02 & 16.58 & \\
\hline ermo03 & & 1.007 & Thermo03 & & 1.007 & Thermo03 & & 1.009 & Thermo03 & & 1.009 & Thermo03 & 15.69 & 1.009 & hermo03 & 7.31 & 1.084 & & 15 & 1.034 \\
\hline termo02 & 14.55 & & Thermo02 & 1365 & & Thermo02 & 1 & & Thermo02 & 14.80 & & Thermo02 & 15.54 & & hermo02 & 16.05 & & 002 & 16.61 & \\
\hline no03 & 14 & 1.008 & hermo03 & & 0 & 03 & & 15 & 1003 & & o9 & 03 & 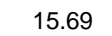 & 10 & & 17.27 & 70 & & 17.18 & 1.034 \\
\hline 1002 & 1 & & Thermo02 & 1 & & Thermo02 & 14.2 & & 1002 & 14.81 & & 1002 & 15.55 & & 002 & 16.22 & & 002 & 16.62 & \\
\hline ermo03 & 14 & 1.008 & Thermo03 & 13.7 & 1.007 & Thermo03 & 14.3 & 1.008 & Thermo03 & 14.9 & 1.009 & Thermo03 & 15.69 & 1.009 & Thermo03 & 17.22 & 1.056 & The & 17.18 & 1.034 \\
\hline Thermo02 & 14.53 & & Thermo02 & 13.63 & & Thermo02 & 14.21 & & Thermo02 & 14.82 & & Thermo02 & 15.54 & & Thermo02 & 16.38 & & Thermo02 & 16.62 & \\
\hline $30 \mu \mathrm{g} / \mathrm{m}^{3}$ & & & $30 \mu \mathrm{g} / \mathrm{m}^{3}$ & & & $30 \mu \mathrm{g} / \mathrm{m}^{3}$ & & & $30 \mu \mathrm{g} / \mathrm{m}^{3}$ & & & $30 \mu \mathrm{g} / \mathrm{m}^{3}$ & & & $30 \mu \mathrm{g} / \mathrm{m}^{3}$ & & & $30 \mu \mathrm{g} / \mathrm{m}^{3}$ & & \\
\hline Thermo02 & 28.58 & & $\overline{\text { Thermo02 }}$ & 26.89 & & $\overline{\text { Thermo02 }}$ & 28. & & $\overline{\text { Thermo02 }}$ & 29.14 & & $\overline{\text { Thermo02 }}$ & 30. & & $\overline{\text { Thermo } 02}$ & 28.32 & & $\overline{\text { Thermo02 }}$ & 32.52 & \\
\hline 1003 & & 1.036 & 03 & & 1.038 & 03 & & 1.038 & 03 & & 1.036 & 003 & 3 & 1.035 & & 45 & 1.208 & & & 1.055 \\
\hline $\mathrm{mo02}$ & 2 & & Thermo02 & 26 & & The & 27. & & ermo02 & 29.1 & & Thermo02 & 30.5 & & no02 & 28.72 & & 002 & 32.50 & \\
\hline $\mathrm{mo03}$ & & 1.036 & Thermo03 & & 1.038 & Ther & & 1.037 & ermo03 & & 1.037 & Thermo03 & 31 & 1.035 & 003 & 34.29 & 1.191 & & 34.30 & 1.055 \\
\hline no02 & & & ermo02 & & & 02 & 27 & & amo02 & 29 & & Thermo02 & 30 & & 002 & 28.86 & & 02 & 32.49 & \\
\hline Thermo03 & 29.56 & 1.037 & Thermo03 & 27.91 & 1.038 & Thermo03 & 29.00 & 1.038 & 003 & 30.1 & 1.037 & Thermo03 & 31.61 & 1.035 & 1003 & 34.19 & 1.180 & 003 & 34.30 & 1.056 \\
\hline Thermo02 & 28.46 & & Thermo02 & 26.88 & & Thermo02 & 27.94 & & Thermo02 & 29.04 & & Thermo02 & 30.53 & & Thermo02 & 29.09 & & Thermo02 & 32.49 & \\
\hline$g / m^{3}$ & & & 50 & & & 50 & & & $50 \mu \mathrm{g} / \mathrm{m}^{3}$ & & & 50 & & & $50 \mu \mathrm{g} / \mathrm{m}^{3}$ & & & & & \\
\hline $\mathrm{mo02}$ & 46.5 & & & 44. & & & & & rmo02 & 47 & & $\mathrm{no02}$ & 49 & & no02 & 40.58 & & & 53.25 & \\
\hline no03 & 4 & 1.058 & Thermo03 & 46.71 & 1.055 & Ther & 48. & 1.055 & rmo03 & 50.2 & 1.059 & Thermo03 & 52.67 & 1.065 & Thermo03 & 56.42 & 1.387 & 03 & 56.79 & 1.067 \\
\hline & & & & & & & & & & 47 & & & 49 & & & 40.77 & & & 21 & \\
\hline Thermo03 & 49.1 & 1.059 & Thermo03 & 46.62 & 1.055 & Thermo03 & 48. & 1.056 & Thermo03 & 50.22 & 1.061 & Thermo03 & 52.62 & 1.074 & Thermo03 & 56.31 & 1.377 & 1003 & 56.73 & 1.067 \\
\hline & & & & & & & & & & 47 & & & 48.72 & & & 41.00 & & & 53.14 & \\
\hline no03 & 49.04 & 1.060 & 003 & 46 & 1.055 & & 48 & 1.058 & 003 & 50.15 & 1.063 & Thermo03 & 52.39 & 1.080 & Thermo03 & 56.18 & 1.356 & 003 & 56.66 & 1.067 \\
\hline Thermo02 & 46.17 & & Thermo02 & 44.14 & & Thermo02 & 45.77 & & Thermo02 & 47.11 & & Thermo02 & 48.29 & & Thermo02 & 41.85 & & Thermo02 & 53.08 & \\
\hline Ig Zero -c & $460 \mu \mathrm{g} / \mathrm{m}$ & & $H g^{\circ}$ Zero - & $319 \mu \mathrm{g} / \mathrm{m}^{3}$ & & $H^{\circ}$ Zero - & $261 \mu \mathrm{g} / \mathrm{m}^{3}$ & & $H^{\circ}$ Zero - & $0.0102 \mu$ & & $\mathrm{Hg}^{\circ}$ Zero $\mathrm{O}$. & $.00645 \mu \mathrm{g}$ & & $\mathrm{Hg}^{\circ}$ Zero $-\mathrm{C}$ & $0.027 / 7$ & & $H g^{\circ}<$ & $0.000 / \mathrm{s}$ & \\
\hline
\end{tabular}


Although this limited experience might not be representative of all units, a caution flag should be raised about elemental mercury source passivation failures and the absolutely critical issue of air and nitrogen gas quality. In the initial work described in this report, carbon scrubber cartridges were not in use. Recently we have installed carbon scrubber cartridges provided by Thermo Fisher in the compressed air lines near the calibrator inlets and Tekran air purification cartridge manifolds at the compressor outlets, however even this is not sufficient to prevent source passivation. It should be noted that during our work with other vendor units in 2007, we have encountered source passivation incidents also, including the onset apparent elemental mercury surface contamination for one type of design, which employs a single 75 microliter drop of elemental mercury as the source. Although this unit is operated exclusively on ultra high purity (UHP) nitrogen, the source failed repeatedly every few weeks of continued use, and operation was immediately restored by replacing the mercury micro drop. It is unknown what type of skin is forming on the outside surface of the micro drop to prevent equilibrium vaporization of the mercury. One thing in common with all of the units used at WRI is the use of 20-50 feet of relatively fresh $1 / 4$-inch i.d. PFA tubing, which can release small quantities of fluorinated oligomers into the delivery air stream.

Based on the above observations, some speculations can be made. It seems possible that a sufficient amount of mercury in the source with the ability to replenish its exposed surface is key to long term reliability. In addition, if a certain type of air or nitrogen purity is absolutely required to operate these units, it needs to be highlighted in the operating manuals as a critical requirement. We recommend that the calibrator vendors specify an air quality requirement consistent with an international standard such as ISO 8573.1 Class 1 dirt (0.1 micron), Class 2 water $\left(-40^{\circ} \mathrm{C}\right.$ dew point), Class 1 oil $\left(0.01 . \mathrm{mg} / \mathrm{m}^{3}\right)$ specification air quality, for example. In addition, careful attention needs to be paid to the type of tubing used and required pretreatment to minimize potential volatiles release.

\section{ELEMENTAL GENERATOR QUALIFICATION EXPERIMENTS}

According to the draft interim traceability protocols, the elemental mercury calibrator qualification experiments that must be performed by the vendors include evaluation of the effects of several variables on calibrator concentration output (EPA 2007). These include back pressure, ambient pressure, temperature, and line voltage. The qualification test criteria should be very specific in what is needed, yet relatively simple to perform. It will be important to define exactly what data need to be obtained with each experiment, with some guidance as to how the tests should be conducted. This will eliminate confusion amongst the vendors, who would prefer not

to generate data only to find later that it is not sufficient. The protocol also should provide equations to calculate the percent variability values. Once data are generated, values that are reasonable and achievable should be used as acceptance criteria in a revised protocol. The 
purpose of the qualification tests is to rapidly evaluate and document that a vendor design performs as required.

In a related mercury calibrator project, simple draft qualification testing protocols were developed (Schabron et al. 2008). These involve a series of 3 x 3 matrixes ( 3 concentrations, 3 variable conditions) for each variable. As part of the current effort, Thermo $80 \mathrm{i}$ calibrator output was evaluated using three nominal concentration settings of 5,15 , and $30 \mu \mathrm{g} / \mathrm{m}^{3}$. Variables evaluated include back pressure, ambient pressure, ambient temperature, and line voltage. For back pressure, the conditions were as follows: no pressure applied, 5 psi, and 9 psi back pressure applied in alternating sequences, while the concentrations were read from the $80 \mathrm{i}$ spectrometer. CEM umbilicals are not expected to cause greater than 9 psi back pressure. Back pressure experiments did not require nesting of two separate calibrators. For ambient pressure evaluation, the calibrator being evaluated was placed in a pressure controlled chamber, and a nesting analysis was performed against another calibrator outside the chamber. Pressures evaluated were $0.78,0.95$, and $1.1 \mathrm{~atm}$. For ambient temperature evaluation, the calibrator being evaluated was placed in a temperature controlled environmental chamber, and a nesting analysis was performed against another calibrator at ambient temperature outside the chamber. Three temperatures studied were 10, 20, and $30^{\circ} \mathrm{C}$. Line voltage effects were studied using a Variac unit. Experiments were conducted at three line voltage settings: 105, 115, and 125 Volts.

\section{Calibrator Linearity Output Profiles}

The elemental mercury response profile for the Thermo 02 calibrator was determined for nine nominal concentration settings ranging from 3 to $30 \mu \mathrm{g} / \mathrm{m}^{3}$. To confirm the efficacy of the new 3/8" vent configuration, the analyzer's chamber pressure was recorded for each concentration and flow rate produced by the calibrators to the vent and analyzer. Linearity results for the Thermo $0281 \mathrm{i}$ calibrator are provided in Table 3 and plotted in Figure 2. The actual flow rates delivered by the $81 \mathrm{i}$ depend on the length of $1 / 4$ " i.d. tubing used to deliver the $\mathrm{Hg}$ vapor to the analyzer. The length of tubing provides some restriction to flow, which is investigated and described in the Back Pressure section of this report. The length of tubing used for every calibrator was kept as a constant, and was 7 feet for these initial studies. In later work, $3 / 8$ " i.d. tubing was used. Linearity results for the Thermo 03 calibrator are presented in Table 4 and plotted in Figure 3. 
Table 3. Response Data for Thermo 02 Calibrator

\begin{tabular}{|c|c|c|c|c|}
\hline Thermo02 & Setpoint, $\mu \mathrm{g} / \mathrm{m}^{3}$ & $\underline{80 \mathrm{i} \mu \mathrm{g} / \mathrm{m}^{3}}$ & 80i chamber, $\mathrm{mm} \mathrm{Hg}$ & $\sim$ Flow Rate \\
\hline 1 & 3.00 & 3.16 & 23.94 & $16.1 \mathrm{~L} / \mathrm{min}$ \\
\hline 2 & 4.00 & 4.20 & 24.24 & $14.5 \mathrm{~L} / \mathrm{min}$ \\
\hline 3 & 5.00 & 5.24 & 23.94 & $13.4 \mathrm{~L} / \mathrm{min}$ \\
\hline 4 & 7.50 & 7.88 & 23.94 & $11.8 \mathrm{~L} / \mathrm{min}$ \\
\hline 5 & 10.00 & 10.50 & 23.94 & $11.0 \mathrm{~L} / \mathrm{min}$ \\
\hline 6 & 12.50 & 13.11 & 23.94 & $10.4 \mathrm{~L} / \mathrm{min}$ \\
\hline 7 & 15.00 & 15.67 & 23.94 & $10.1 \mathrm{~L} / \mathrm{min}$ \\
\hline 8 & 20.00 & 20.70 & 23.94 & $9.6 \mathrm{~L} / \mathrm{min}$ \\
\hline 9 & 30.00 & 30.05 & 23.94 & $9.1 \mathrm{~L} / \mathrm{min}$ \\
\hline
\end{tabular}

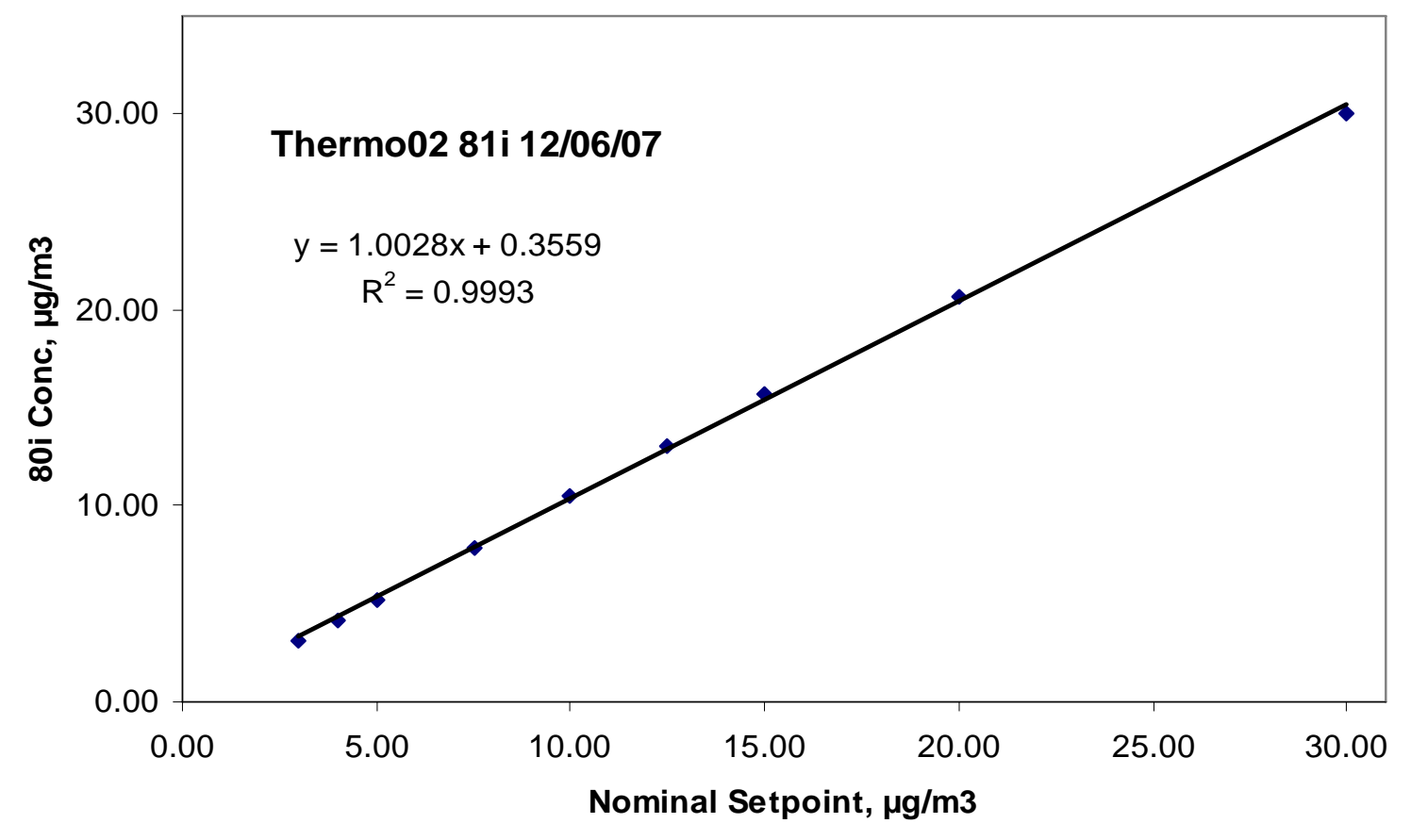

Figure 2. Linear Response Profile for Thermo 02 Calibrator 
Table 4. Response Data for the Thermo 03 Calibrator

\begin{tabular}{|c|c|c|c|}
\hline Thermo03 & $\underline{\text { Setpoint, } \mu \mathrm{g} / \mathrm{m}^{3}}$ & $\underline{80 \mathrm{i} \mu \mathrm{g} / \mathrm{m}^{3}}$ & 80i chamber, $\mathrm{mm} \mathrm{Hg}$ \\
\hline 1 & 3.00 & 3.12 & 23.94 \\
\hline 2 & 4.00 & 4.22 & 23.94 \\
\hline 3 & 5.00 & 5.30 & 23.94 \\
\hline 4 & 7.50 & 8.01 & 23.94 \\
\hline 5 & 10.00 & 10.73 & 23.94 \\
\hline 6 & 12.50 & 13.44 & 23.65 \\
\hline 7 & 15.00 & 16.14 & 23.94 \\
\hline 8 & 20.00 & 21.63 & 23.94 \\
\hline 9 & 30.00 & 32.56 & 23.94 \\
\hline
\end{tabular}

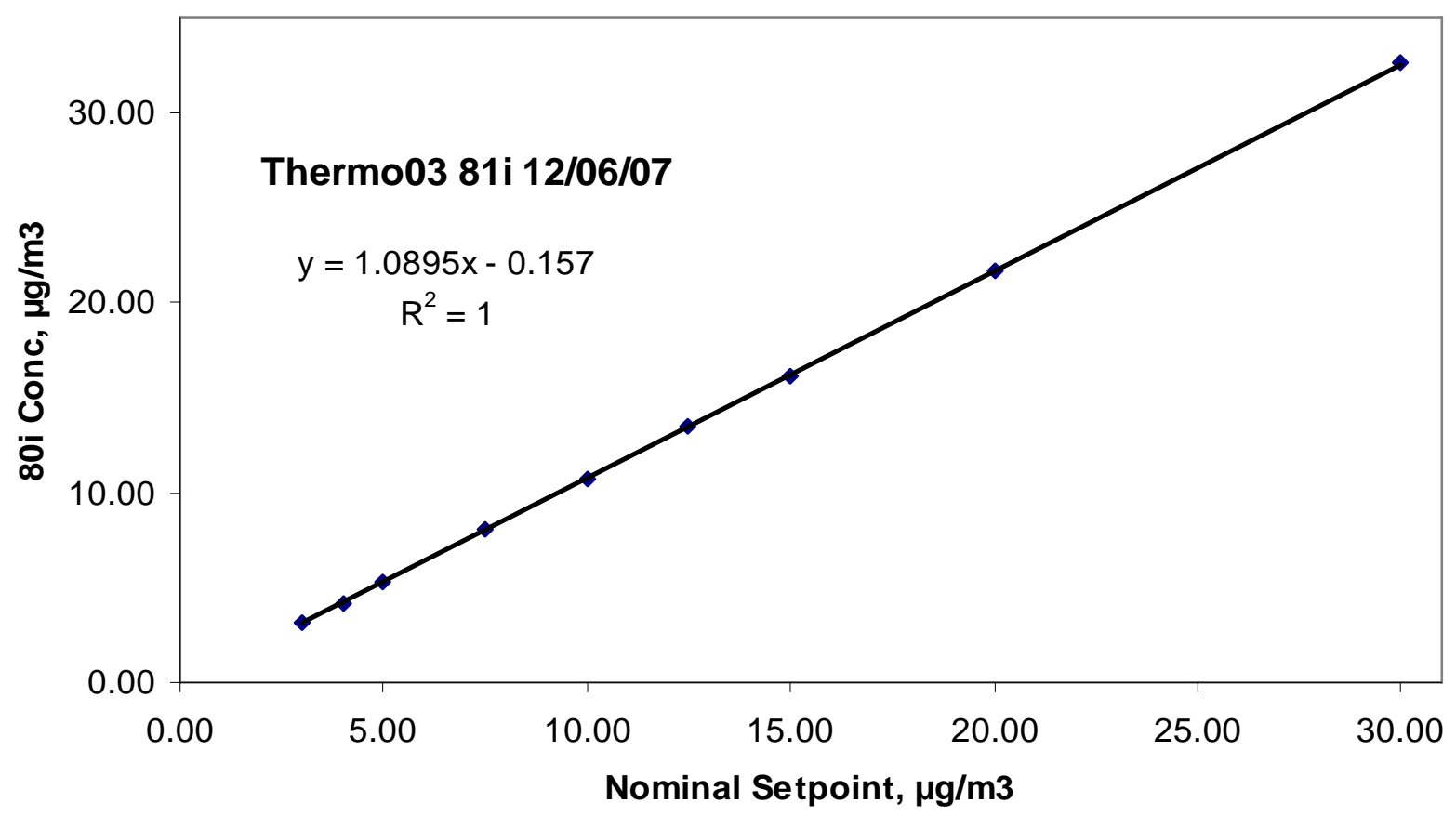

Figure 3. Linear Response Profile for Thermo 03 Calibrator

\section{Effect of Back Pressure on Calibrator Output}

A series of back pressures were applied to the elemental mercury output ports of the calibrators. These were intended to simulate a variety of field conditions where long lengths of tubing, such as those used for umbilical lines for CEM probes, may apply a back pressure as high 
as $0.61 \mathrm{~atm}(9 \mathrm{psi})$ to a calibrator's vapor outlet port. Effects due to back pressure were measured by recording the mercury vapor concentration changes, if any, produced by the calibrators with output flow restrictions. Back pressure was applied to the elemental mercury vapor outlet port of the calibrators using a needle valve constructed of PFA (Swagelok P/N PFA-4RPS4). The pressure was measured using a digital pressure indicator (Omega DPI 705) mounted to a "tee" situated between the valve and the calibrator's outlet port.

A photo of the device is provided in Figure 4. In the photo, the calibrator is to the far left and the analyzer is to the far right. The valve is designed so that three counter-clockwise rotations of the handle correspond to a wide-open valve. Three back pressure conditions were applied in bracketed sequences of 15-minute intervals for three nominal concentration settings. The bracketed sequence and experimental results for the Therm02 calibrator are presented in Table 5 .

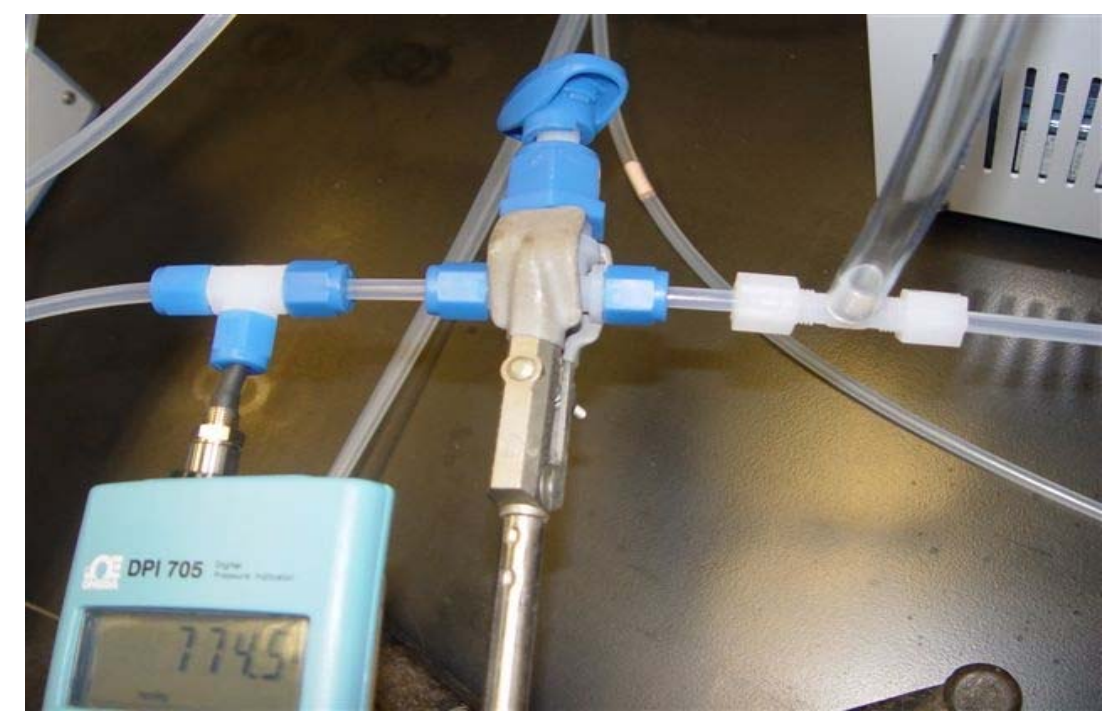

Figure 4. Back Pressure Experiment Valve 
Table 5. Back Pressure Data for Thermo 02 Calibrator Cal Gas Outlet

\begin{tabular}{|c|c|c|c|c|c|c|}
\hline Thermo02 81i Cal Gas Port & $\underline{\text { Valve }}$ & Backpressure, $\mathrm{mmHg}$ & Pressure Ratio & 80i 5-min avg, $\mu \mathrm{g} / \mathrm{m} 3$ & Nested Rel. \% Diff. & 81i MFC2 (Dil) Flow \\
\hline \multirow[t]{10}{*}{$5.00 \mu \mathrm{g} / \mathrm{m} 3$ Nominal } & 3 rotations open & 605.6 & 1.00 & 5.16 & & \\
\hline & $7 / 8$ rotation open & 785.5 & 1.30 & 5.14 & $0.1 \%$ & \\
\hline & $5 / 8$ rotation open & 962.1 & 1.59 & 5.12 & $0.5 \%$ & \\
\hline & 3 rotations open & 605.7 & 1.00 & 5.13 & & \\
\hline & $7 / 8$ rotation open & 783.8 & 1.29 & 5.12 & $0.1 \%$ & \\
\hline & $5 / 8$ rotation open & 964.0 & 1.59 & 5.11 & $0.3 \%$ & \\
\hline & 3 rotations open & 605.7 & 1.00 & 5.12 & & 14.1 L/min \\
\hline & $7 / 8$ rotation open & 783.9 & 1.29 & 5.13 & $0.1 \%$ & $12.5 \mathrm{~L} / \mathrm{min}$ \\
\hline & $5 / 8$ rotation open & 972.0 & 1.60 & 5.10 & $0.5 \%$ & $10.9 \mathrm{~L} / \mathrm{min}$ \\
\hline & 3 rotations open & 605.6 & 1.00 & 5.13 & & $14.1 \mathrm{~L} / \mathrm{min}$ \\
\hline \multirow[t]{10}{*}{$15.00 \mu \mathrm{g} / \mathrm{m} 3$ Nominal } & 3 rotations open & 596.7 & 1.00 & 15.27 & & \\
\hline & $7 / 8$ rotation open & 792.7 & 1.33 & 15.32 & $0.4 \%$ & \\
\hline & $5 / 8$ rotation open & 890.4 & 1.49 & 15.35 & $0.6 \%$ & \\
\hline & 3 rotations open & 596.5 & 1.00 & 15.25 & & \\
\hline & $7 / 8$ rotation open & 785.6 & 1.32 & 15.28 & $0.3 \%$ & \\
\hline & $5 / 8$ rotation open & 966.8 & 1.62 & 15.28 & $0.3 \%$ & \\
\hline & 3 rotations open & 596.0 & 1.00 & 15.22 & & 10.6 L/min \\
\hline & $7 / 8$ rotation open & 776.8 & 1.30 & 15.26 & $0.4 \%$ & $9.0 \mathrm{~L} / \mathrm{min}$ \\
\hline & $5 / 8$ rotation open & 939.3 & 1.58 & 15.32 & $0.8 \%$ & $7.8 \mathrm{~L} / \mathrm{min}$ \\
\hline & 3 rotations open & 596.2 & 1.00 & 15.19 & & 10.6 L/min \\
\hline \multirow[t]{10}{*}{$30.00 \mu \mathrm{g} / \mathrm{m} 3$ Nominal } & 3 rotations open & 594.0 & 1.00 & 30.12 & & \\
\hline & $7 / 8$ rotation open & 770.9 & 1.30 & 30.27 & $0.7 \%$ & \\
\hline & $5 / 8$ rotation open & 944.2 & 1.59 & 30.32 & $0.8 \%$ & \\
\hline & 3 rotations open & 594.2 & 1.00 & 30.02 & & \\
\hline & $7 / 8$ rotation open & 768.7 & 1.29 & 30.28 & $1.0 \%$ & \\
\hline & $5 / 8$ rotation open & 950.7 & 1.60 & 30.29 & $1.0 \%$ & \\
\hline & 3 rotations open & 594.0 & 1.00 & 29.95 & & $9.5 \mathrm{~L} / \mathrm{min}$ \\
\hline & $7 / 8$ rotation open & 774.6 & 1.30 & 30.17 & $0.8 \%$ & $8.0 \mathrm{~L} / \mathrm{min}$ \\
\hline & $5 / 8$ rotation open & 953.1 & 1.60 & 30.23 & $1.0 \%$ & $6.8 \mathrm{~L} / \mathrm{min}$ \\
\hline & 3 rotations open & 594.0 & 1.00 & 29.91 & & $9.5 \mathrm{~L} / \mathrm{min}$ \\
\hline
\end{tabular}

The amount of back pressure was read at the digital pressure indicator. The pressure ratios in the table above are indicative of the relative amounts of back pressure applied above the ambient back pressure (valve wide open). The nested relative percent difference values are a measure of the back pressure effect on concentration output. The concentration results are in good agreement with the response profiles generated above (in which the slope was determined to be 1.00). The dilution flow rate listed on the far right of the table shows that the $81 \mathrm{i}$ compensates for flow restriction by lowering the dilution flow output.

The previous data were obtained with the back pressure applied to the Cal Gas outlet port of the 81i. Alternately, the Probe Port outlet was used; these data are presented in Table 6. The cal gas port is connected to an internal 3 psi pressure relieve valve and the excess pressure is vented through a carbon sorbent bed. 
Table 6. Back Pressure Data for Thermo 02 Calibrator Probe Port Outlet

\begin{tabular}{|c|c|c|c|c|c|c|}
\hline Thermo02 81i Probe Port & Valve & Backpressure, $\mathrm{mmHg}$ & Pressure Ratio & 80i 5-min avg, $\mu \mathrm{g} / \mathrm{m} 3$ & Nested Rel. \% Diff. & 81i MFC2 (Dil) Flow \\
\hline \multirow[t]{10}{*}{$5.00 \mu \mathrm{g} / \mathrm{m} 3$ Nominal } & 3 rotations open & 605.2 & 1.00 & 5.19 & & \\
\hline & $7 / 8$ rotation open & 781.5 & 1.29 & 5.15 & $0.4 \%$ & \\
\hline & $5 / 8$ rotation open* & 740.8 & 1.22 & 5.14 & $0.6 \%$ & \\
\hline & 3 rotations open & 605.6 & 1.00 & 5.15 & & \\
\hline & $7 / 8$ rotation open & 793.0 & 1.31 & 5.13 & $0.1 \%$ & \\
\hline & $5 / 8$ rotation open* & 763.7 & 1.26 & 5.11 & $0.3 \%$ & \\
\hline & 3 rotations open & 605.9 & 1.00 & 5.12 & & $14.5 \mathrm{~L} / \mathrm{min}$ \\
\hline & $7 / 8$ rotation open & 780.6 & 1.29 & 5.12 & $0.1 \%$ & $12.8 \mathrm{~L} / \mathrm{min}$ \\
\hline & $5 / 8$ rotation open* & 761.8 & 1.26 & 5.12 & $0.1 \%$ & $13.0 \mathrm{~L} / \mathrm{min}$ \\
\hline & 3 rotations open & 606.1 & 1.00 & 5.13 & & $14.5 \mathrm{~L} / \mathrm{min}$ \\
\hline \multirow[t]{10}{*}{$15.00 \mu \mathrm{g} / \mathrm{m} 3$ Nominal } & 3 rotations open & 597.9 & 1.00 & 15.38 & & \\
\hline & $7 / 8$ rotation open & 772.6 & 1.29 & 15.35 & $0.2 \%$ & \\
\hline & $5 / 8$ rotation open* & 707.0 & 1.18 & 15.32 & $0.03 \%$ & \\
\hline & 3 rotations open & 597.7 & 1.00 & 15.27 & & \\
\hline & $7 / 8$ rotation open & 781.5 & 1.31 & 15.29 & $0.3 \%$ & \\
\hline & $5 / 8$ rotation open* & 684.1 & 1.14 & 15.25 & $0.03 \%$ & \\
\hline & 3 rotations open & 597.3 & 1.00 & 15.22 & & $10.8 \mathrm{~L} / \mathrm{min}$ \\
\hline & $7 / 8$ rotation open & 763.4 & 1.28 & 15.23 & $0.2 \%$ & $9.2 \mathrm{~L} / \mathrm{min}$ \\
\hline & $5 / 8$ rotation open $*$ & 680.9 & 1.14 & 15.20 & $0.0 \%$ & $10.0 \mathrm{~L} / \mathrm{min}$ \\
\hline & 3 rotations open & 597.2 & 1.00 & 15.18 & & $10.8 \mathrm{~L} / \mathrm{min}$ \\
\hline \multirow[t]{10}{*}{$30.00 \mu \mathrm{g} / \mathrm{m} 3$ Nominal } & 3 rotations open & 594.9 & 1.00 & 30.12 & & \\
\hline & $7 / 8$ rotation open & 768.4 & 1.29 & 30.33 & $1.0 \%$ & \\
\hline & $5 / 8$ rotation open* & 677.2 & 1.14 & 30.16 & $0.4 \%$ & \\
\hline & 3 rotations open & 594.9 & 1.00 & 29.96 & & \\
\hline & $7 / 8$ rotation open & 766.1 & 1.29 & 30.20 & $1.0 \%$ & \\
\hline & $5 / 8$ rotation open* & 678.2 & 1.14 & 30.02 & $0.4 \%$ & \\
\hline & 3 rotations open & 594.9 & 1.00 & 29.86 & & $9.7 \mathrm{~L} / \mathrm{min}$ \\
\hline & $7 / 8$ rotation open & 752.3 & 1.26 & 30.08 & $0.9 \%$ & $8.3 \mathrm{~L} / \mathrm{min}$ \\
\hline & $5 / 8$ rotation open* & 666.1 & 1.12 & 29.91 & $0.3 \%$ & $9.0 \mathrm{~L} / \mathrm{min}$ \\
\hline & 3 rotations open & 594.7 & 1.00 & 29.77 & & $9.7 \mathrm{~L} / \mathrm{min}$ \\
\hline
\end{tabular}

With the Probe Port outlet, the internal check valve with 3 psi crack pressure limits the amount of back pressure that can be applied to the calibrator. Therefore, the back pressure applied at the $5 / 8$ rotation position is actually less than that applied at the $7 / 8$ position. The effect of the internal vent is evident in the flow rate data. The concentration results are also in agreement with the previous response profile data. There is no significant effect on concentration outputs due to back pressure.

\section{Effect of Line Voltage on Calibrator Output}

A Variac Model TDGC-2KM was used to alter the line voltage for the calibrators. A photo of the Variac with a Thermo $81 \mathrm{i}$ calibrator is provided in Figure 5. 


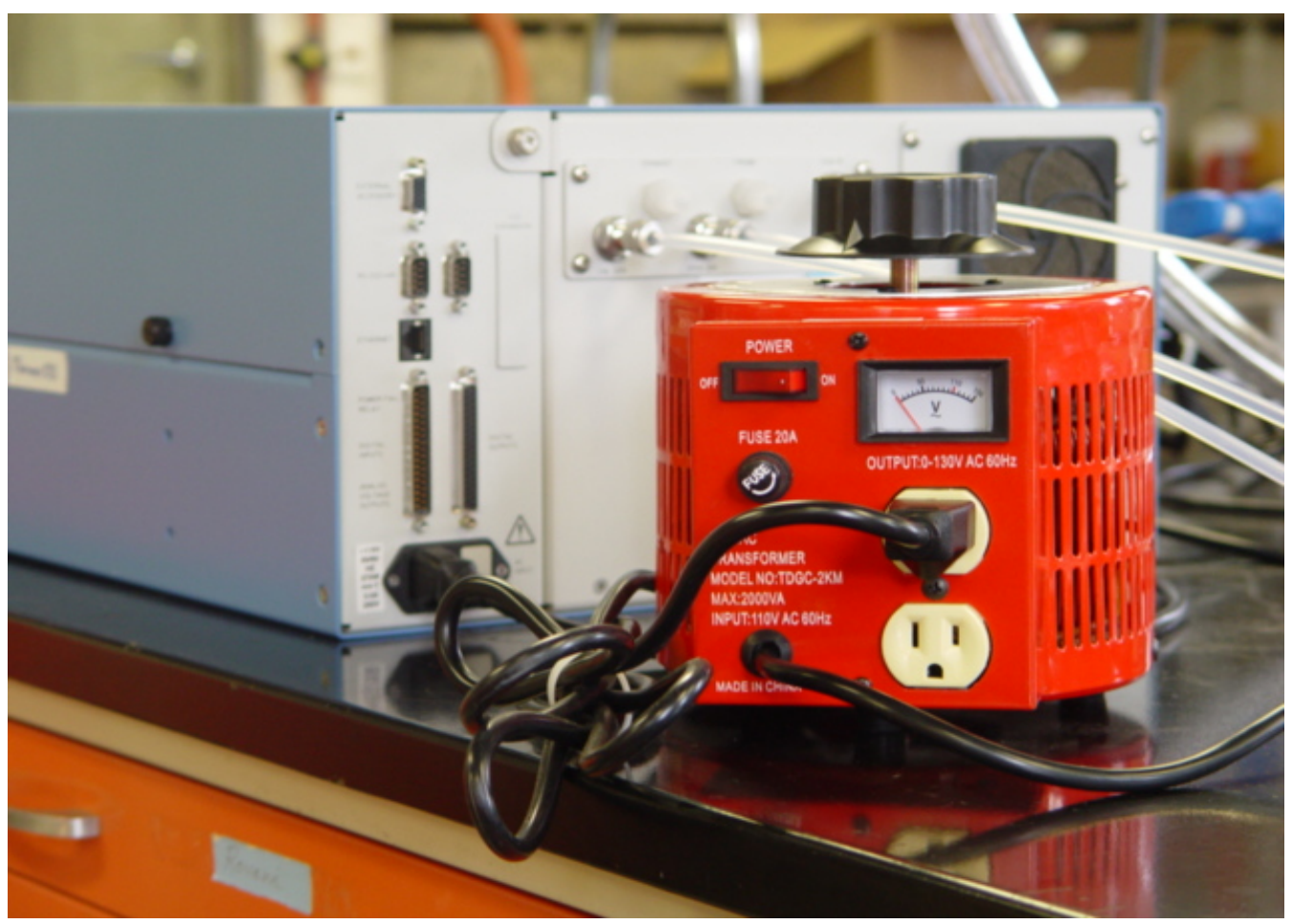

Figure 5. Variac Unit for Line Voltage Experiments

The probe tips of a Fluke Model 79 multimeter were inserted in the unused outlet of the Variac to measure line voltage. The Variac was dialed to $105.0 \pm 0.1,115.0 \pm 0.1$, and $125.0 \pm$ 0.1 VAC. The results obtained for the Thermo 02 calibrator Cal Gas port are presented in Table 7. The experimental sequence used was an intra-unit sequence (testing performed on one unit at a time) similar to that used for backpressure. The concentration results for test conditions of 105 and $125 \mathrm{VAC}$ were nested within brackets of $115 \mathrm{VAC}$ control conditions. The relative percent difference values were calculated to determine the effect of varying the line voltage. Ten-minute equilibration timeframes were used between readings. 
Table 7. Line Voltage Variation Data for Thermo 02 Calibrator

\begin{tabular}{|c|c|c|c|}
\hline Thermo02 81i Cal Gas Port & Line VAC $( \pm 0.1 \mathrm{~V})$ & 80i 5-min avg, $\mu \mathrm{g} / \mathrm{m} 3$ & Nested Rel. \% Diff. \\
\hline \multirow{10}{*}{$5.00 \mu \mathrm{g} / \mathrm{m} 3$ Nominal } & 115.0 & 4.90 & \\
\hline & 105.0 & 4.89 & $0.2 \%$ \\
\hline & 125.0 & 4.86 & $0.4 \%$ \\
\hline & 115.0 & 4.86 & \\
\hline & 105.0 & 4.85 & $0.2 \%$ \\
\hline & 125.0 & 4.85 & $0.2 \%$ \\
\hline & 115.0 & 4.86 & \\
\hline & 105.0 & 4.84 & $0.3 \%$ \\
\hline & 125.0 & 4.83 & $0.3 \%$ \\
\hline & 115.0 & 4.83 & \\
\hline \multirow{10}{*}{$15.00 \mu \mathrm{g} / \mathrm{m} 3$ Nominal } & 115.0 & 14.68 & \\
\hline & 105.0 & 14.66 & $0.1 \%$ \\
\hline & 125.0 & 14.64 & $0.03 \%$ \\
\hline & 115.0 & 14.61 & \\
\hline & 105.0 & 14.60 & $0.1 \%$ \\
\hline & 125.0 & 14.60 & $0.1 \%$ \\
\hline & 115.0 & 14.57 & \\
\hline & 105.0 & 14.57 & $0.1 \%$ \\
\hline & 125.0 & 14.56 & $0.0 \%$ \\
\hline & 115.0 & 14.55 & \\
\hline \multirow[t]{10}{*}{$30.00 \mu \mathrm{g} / \mathrm{m} 3$ Nominal } & 115.0 & 28.65 & \\
\hline & 105.0 & 28.61 & $0.04 \%$ \\
\hline & 125.0 & 28.59 & $0.04 \%$ \\
\hline & 115.0 & 28.55 & \\
\hline & 105.0 & 28.52 & $0.02 \%$ \\
\hline & 125.0 & 28.50 & $0.05 \%$ \\
\hline & 115.0 & 28.48 & \\
\hline & 105.0 & 28.48 & $0.1 \%$ \\
\hline & 125.0 & 28.46 & $0.1 \%$ \\
\hline & 115.0 & 28.41 & \\
\hline
\end{tabular}

Although the effect of line voltage as determined by the change in nested relative percent difference results is almost negligible, there is a noticeable downward drift in the concentration results. The line voltage test was repeated using an inter-unit sequence (testing performed using one unit as a test case and another unit as a control). The Thermo 02 calibrator was used as the test instrument $(105,125 \mathrm{VAC})$ and the Thermo 03 unit was used as the control (115 VAC). The results for a nominal concentration setting of $15 \mu \mathrm{g} / \mathrm{m}^{3}$ are presented in Table 8 .

The slight downward drift is evident again but in both Thermo 02 and Thermo 03 calibrators. This suggested that the analyzer was the likely cause of the apparent drift. One possible scenario is the analyzer lamp is drifting slightly. A plot of the lamp intensity during the $30 \mu / \mathrm{m}^{3}$ intra-unit sequence is shown in Figure 6. This shows a $0.7 \%$ drift in 100 minutes. The use of nesting comparison experiments compensates for the minor analyzer drift effects (Table $8)$. 
Table 8. Nested Line Voltage Variation Data for Thermo 02 Calibrator

\begin{tabular}{|ccccc|}
\hline Calibrator & Line VAC $( \pm 0.1 V)$ & 80i 5-min $\mathbf{a v g}, \mu \mathrm{g} / \mathrm{m} 3$ & & Nested Ratio \\
\cline { 1 - 2 } Thermo03 & ambient & 15.55 & \\
Thermo02 & 115.0 & 14.86 & 0.957 \\
Thermo03 & ambient & 15.52 & \\
Thermo02 & 105.0 & 14.84 & 0.956 \\
Thermo03 & ambient & 15.51 & \\
Thermo02 & 125.0 & 14.83 & 0.957 \\
Thermo03 & ambient & 15.49 & \\
Thermo02 & 115.0 & 14.81 & 0.956 \\
Thermo03 & ambient & 15.48 & \\
Thermo02 & 105.0 & 14.81 & 0.957 \\
Thermo03 & ambient & 15.47 & \\
Thermo02 & 125.0 & 14.80 & 0.957 \\
Thermo03 & ambient & 15.47 & \\
\hline
\end{tabular}

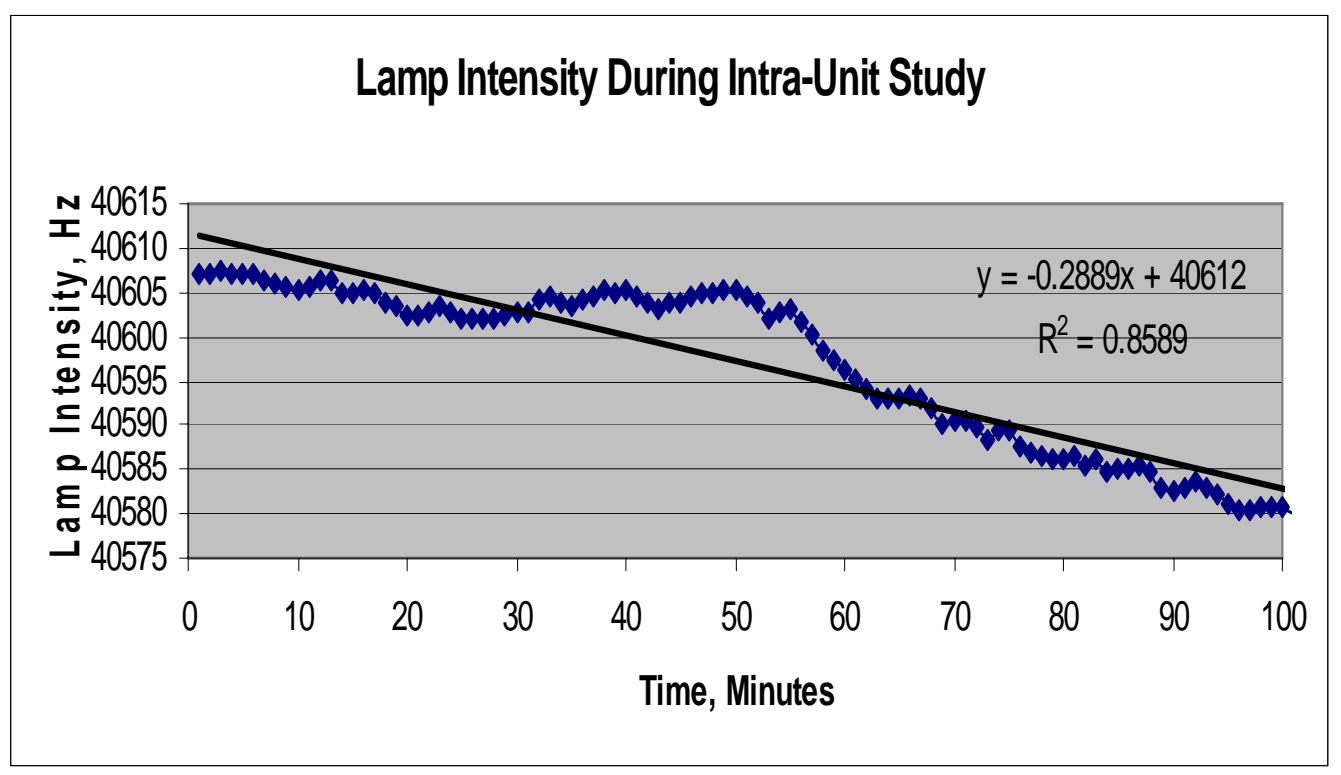

Figure 6. Drift in Thermo 80i Lamp Intensity

The line voltage dependent variability for the Thermo 02 unit was $0.4 \%$ or less at all three line voltages and concentrations studied. This is a negligible effect. 


\section{Effect of Ambient Temperature on Calibrator Output}

To investigate the effect of environmental temperature on the elemental mercury vapor concentration delivered, the Thermo 02 unit was placed inside a Revco Model RTC30-99D Stability Test Chamber. A photo of the chamber is shown in Figure 7.

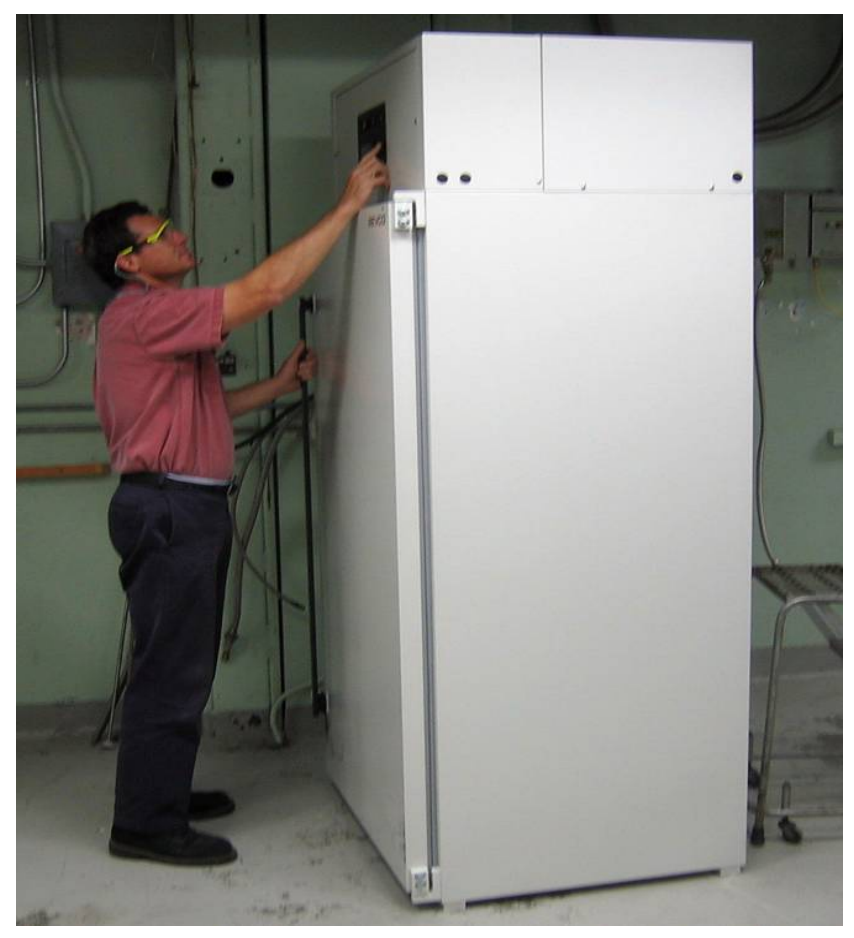

Figure 7. Environmental Chamber for Ambient Temperature Experiments

The Thermo 02 unit in the test chamber was operated at temperatures of $30^{\circ} \mathrm{C}, 20^{\circ} \mathrm{C}$, and $10^{\circ} \mathrm{C}$. The elemental mercury vapor concentrations from the test unit were compared to those of the Thermo 03 control unit that was located on an adjacent lab bench at ambient laboratory temperature. The concentrations evaluated were 5,15 , and $30 \mu \mathrm{g} / \mathrm{m}^{3}$. Eight-minute intervals were used for the temperature studies. The concentration values for the test calibrator were compared to the control calibrator using a bracketing sequence, and a nested ratio was calculated.

The experimental data for the $3 \times 3$ matrix are presented in the Tables 9 and 10 . To determine the temperature effect on the elemental mercury concentration delivered by the test calibrator, the nested ratios obtained for each temperature and concentration were compared. The nested ratio variation and average variation were calculated at each concentration. 
Table 9. Ambient Temperature Data for Thermo 02 Calibrator at 20 and $30{ }^{\circ} \mathrm{C}$.

\begin{tabular}{|c|c|c|c|c|c|}
\hline \multicolumn{2}{|c|}{$30^{\circ} \mathrm{C}, 5.00 \mu \mathrm{g} / \mathrm{m} 3$ Nominal } & \multicolumn{4}{|c|}{$20^{\circ} \mathrm{C}, 5.00 \mu \mathrm{g} / \mathrm{m} 3 \mathrm{Nom}$ inal } \\
\hline Calibrator and Temperature & 80i 5-m in avg, $\mu \mathrm{g} / \mathrm{m} 3$ & Nested Ratio & Calibrator and Temperature & 80 i $5-\mathrm{min}$ avg, $\mu \mathrm{g} / \mathrm{m} 3$ & Nested Ratio \\
\hline 1 Thermo03 81i, ambient & 4.89 & & 1 Thermo03 81i, ambient & 4.78 & \\
\hline Thermo02 $81 \mathrm{i}, 30^{\circ} \mathrm{C}$ & 4.73 & 0.968 & Thermo02 $81 \mathrm{i}, 20^{\circ} \mathrm{C}$ & 4.77 & 0.998 \\
\hline 4 Thermo03 81i, ambient & 4.88 & & 4 Thermo03 $81 \mathrm{i}$, ambient & 4.78 & \\
\hline Thermo0281i, $30^{\circ} \mathrm{C}$ & 4.73 & 0.969 & Thermo02 $81 \mathrm{i}, 20^{\circ} \mathrm{C}$ & 4.77 & 1.000 \\
\hline 7 Thermo03 81i, ambient & 4.88 & & 7 Thermo03 81i, ambient & 4.76 & \\
\hline Thermo0281i, $30^{\circ} \mathrm{C}$ & 4.73 & 0.970 & Thermo02 $81 \mathrm{i}, 20^{\circ} \mathrm{C}$ & 4.77 & 1.001 \\
\hline 10 Thermo03 81i, ambient & 4.87 & & 10 Thermo03 81i, ambient & 4.77 & \\
\hline \multicolumn{2}{|c|}{$30^{\circ} \mathrm{C}, 15.00 \mu \mathrm{g} / \mathrm{m} 3$ Nominal } & \multicolumn{3}{|c|}{$20^{\circ} \mathrm{C}, 15.00 \mu \mathrm{g} / \mathrm{m} 3$ Nominal } & \\
\hline Calibrator and Tem pe rature & 80i 5-min avg, $\mu \mathrm{g} / \mathrm{m} 3$ & Nested Ratio & Calibrator and Temperature & 80 i 5-min avg, $\mu \mathrm{g} / \mathrm{m} 3$ & Nested Ratio \\
\hline 1 Thermo03 81i, ambient & 15.08 & & 1 Thermo0381i, ambient & 14.92 & \\
\hline Thermo0 $281 \mathrm{i}, 30^{\circ} \mathrm{C}$ & 14.37 & 0.953 & Thermo02 $81 \mathrm{i}, 20^{\circ} \mathrm{C}$ & 14.44 & 0.968 \\
\hline 4 Thermo03 81i, ambient & 15.08 & & 4 Thermo03 81i, ambient & 14.91 & \\
\hline $5 \quad$ Thermo0 $281 \mathrm{i}, 30^{\circ} \mathrm{C}$ & 14.35 & 0.952 & $5 \quad$ Thermo02 $81 \mathrm{i}, 20^{\circ} \mathrm{C}$ & 14.45 & 0.969 \\
\hline 7 Thermo03 81i, ambient & 15.06 & & 7 Thermo03 81i, ambient & 14.90 & \\
\hline Thermo0 $281 \mathrm{i}, 30^{\circ} \mathrm{C}$ & 14.32 & 0.951 & Thermo02 $81 \mathrm{i}, 20^{\circ} \mathrm{C}$ & 14.44 & 0.971 \\
\hline 10 Thermo03 81i, ambient & 15.05 & & 10 Thermo03 81i, ambient & 14.83 & \\
\hline \multicolumn{2}{|c|}{$30^{\circ} \mathrm{C}, 30.00 \mu \mathrm{g} / \mathrm{m} 3$ Nominal } & \multicolumn{3}{|c|}{$20^{\circ} \mathrm{C}, 30.00 \mu \mathrm{g} / \mathrm{m} 3$ Nominal } & \\
\hline Calibrator and Temperature & 80i 5-m in avg, $\mu \mathrm{g} / \mathrm{m} 3$ & Nested Ratio & Calibrator and Temperature & 80i 5-min avg, $\mu \mathrm{g} / \mathrm{m} 3$ & Nested Ratio \\
\hline 1 Thermo03 81i, ambient & 30.59 & & 1 Thermo0381i, ambient & 30.40 & \\
\hline Thermo0 $281 \mathrm{i}, 30^{\circ} \mathrm{C}$ & 28.68 & 0.940 & Thermo02 $81 \mathrm{i}, 20^{\circ} \mathrm{C}$ & 28.40 & 0.937 \\
\hline 4 Thermo03 81i, ambient & 30.43 & & 4 Thermo03 81i, ambient & 30.22 & \\
\hline Thermo $0281 \mathrm{i}, 30^{\circ} \mathrm{C}$ & 28.57 & 0.940 & Thermo02 $81 \mathrm{i}, 20^{\circ} \mathrm{C}$ & 28.31 & 0.939 \\
\hline 7 Thermo03 81i, ambient & 30.35 & & 7 Thermo03 81i, ambient & 30.10 & \\
\hline Thermo0 $281 \mathrm{i}, 30^{\circ} \mathrm{C}$ & 28.51 & 0.940 & Thermo02 $81 \mathrm{i}, 20^{\circ} \mathrm{C}$ & 28.22 & 0.938 \\
\hline 10 Thermo03 81i, ambient & 30.28 & & 10 Thermo03 81i, ambient & 30.04 & \\
\hline
\end{tabular}

Table 10. Ambient Temperature Data for Thermo 02 Calibrator at $10{ }^{\circ} \mathrm{C}$.

\begin{tabular}{|c|c|c|c|}
\hline \multicolumn{4}{|c|}{$10^{\circ} \mathrm{C}, 5.00 \mu \mathrm{g} / \mathrm{m} 3 \mathrm{Nominal}$} \\
\hline & Calibrator and Temperature & $80 \mathrm{i} 5-\mathrm{min}$ avg, $\mu \mathrm{g} / \mathrm{m} 3$ & Nested Ratio \\
\hline & Thermo03 81i, ambient & 4.79 & \\
\hline 2 & Thermo02 $81 \mathrm{i}, 10^{\circ} \mathrm{C}$ & 4.92 & 1.027 \\
\hline 4 & Thermo03 81i, ambient & 4.79 & \\
\hline 5 & Thermo02 $81 \mathrm{i}, 10^{\circ} \mathrm{C}$ & 4.93 & 1.030 \\
\hline & Thermo03 81i, ambient & 4.78 & \\
\hline 8 & Thermo02 $81 \mathrm{i}, 10^{\circ} \mathrm{C}$ & 4.91 & 1.026 \\
\hline 10 & Thermo03 81i, ambient & 4.79 & \\
\hline \multicolumn{4}{|c|}{$10^{\circ} \mathrm{C}, 15.00 \mu \mathrm{g} / \mathrm{m} 3$ Nominal } \\
\hline & Calibrator and Te mperature & 80i $5-\mathrm{min}$ avg, $\mu \mathrm{g} / \mathrm{m} 3$ & Nested Ratio \\
\hline & Thermo03 81i, ambient & 14.85 & \\
\hline 2 & Thermo02 81i, $10^{\circ} \mathrm{C}$ & 14.57 & 0.982 \\
\hline & Thermo03 81i, ambient & 14.83 & \\
\hline 5 & Thermo02 $81 \mathrm{i}, 10^{\circ} \mathrm{C}$ & 14.53 & 0.980 \\
\hline 7 & Thermo03 81i, ambient & 14.82 & \\
\hline 8 & Thermo02 81i, $10^{\circ} \mathrm{C}$ & 14.49 & 0.978 \\
\hline 10 & Thermo03 81i, ambient & 14.81 & \\
\hline \multicolumn{4}{|c|}{$10^{\circ} \mathrm{C}, 30.00 \mu \mathrm{g} / \mathrm{m} 3 \mathrm{Nominal}$} \\
\hline & Calibrator and Te mperature & $80 i 5-\min$ avg, $\mu \mathrm{g} / \mathrm{m} 3$ & Nested Ratio \\
\hline 1 & Thermo03 81i, ambient & 29.98 & \\
\hline 2 & Thermo02 $81 \mathrm{i}, 10^{\circ} \mathrm{C}$ & 24.90 & 0.831 \\
\hline 4 & Thermo03 81i, ambient & 29.93 & \\
\hline 5 & Thermo02 $81 \mathrm{i}, 10^{\circ} \mathrm{C}$ & 24.58 & 0.823 \\
\hline 7 & Thermo03 81i, ambient & 29.83 & \\
\hline 8 & Thermo02 $81 \mathrm{i}, 10^{\circ} \mathrm{C}$ & 24.41 & 0.819 \\
\hline 10 & $\begin{array}{l}\text { Thermo03 81i, ambient } \\
\text { * Highe st Concen tration That }\end{array}$ & $\begin{array}{c}29.79 \\
\text { d Be Achieved At } 10^{\circ} \mathrm{C}\end{array}$ & \\
\hline
\end{tabular}


The data for the Thermo 02 unit show a significant decrease in its delivered elemental mercury concentration at the $30 \mu \mathrm{g} / \mathrm{m}^{3}$ setting at an operating temperature of $10^{\circ} \mathrm{C}$ (Table 10). A part of the $10^{\circ} \mathrm{C}$ sequence was repeated to determine if the data were an anomaly or if the data could be replicated. These data are provided in Table 11. The data were replicated at all three concentrations.

It appears that an operating temperature of $10{ }^{\circ} \mathrm{C}$ pushes the Thermo 02 unit beyond its capability to reliably deliver elemental mercury vapor at a concentration of $30 \mu \mathrm{g} / \mathrm{m}^{3}$. This may be due to stressing the Peltier devices beyond their capabilities, and operating one or more of the mass flow controllers outside of their certified specification / calibration ranges at the extreme temperatures. The calibrator units should be operated near ambient temperatures of $20{ }^{\circ} \mathrm{C}$. This means that they must be housed and used in rooms with reasonable temperature control. A Qualification acceptance requirement of steady operation between $10-30{ }^{\circ} \mathrm{C}$ is unrealistic.

Table 11. Recheck of Ambient Temperature Data for Thermo 02 Calibrator at $10{ }^{\circ} \mathrm{C}$.

\begin{tabular}{|c|c|c|c|}
\hline \multicolumn{4}{|c|}{ RECHECK OF RESULTS AT $10^{\circ} \mathrm{C}$} \\
\hline \multicolumn{4}{|c|}{$10^{\circ} \mathrm{C}, 5.00 \mu \mathrm{g} / \mathrm{m} 3$ Nominal } \\
\hline \multicolumn{4}{|c|}{ Refe rence Rovani WRI Notebook 1241 Page $2(01 / 18 / 08)$} \\
\hline & Calibrator and Temperature & 80i $5-\mathrm{min}$ avg, $\mu \mathrm{g} / \mathrm{m} 3$ & Nested Ratio \\
\hline 1 & Thermo03 81i, ambient & 4.74 & \\
\hline 2 & Thermo02 $81 \mathrm{i}, 10^{\circ} \mathrm{C}$ & 4.84 & 1.020 \\
\hline 3 & Thermo03 81i, ambient & 4.75 & \\
\hline \multicolumn{4}{|c|}{$10^{\circ} \mathrm{C}, 15.00 \mu \mathrm{g} / \mathrm{m} 3$ Nominal } \\
\hline \multicolumn{4}{|c|}{ Refe rence Rovani WRI Notebook 1241 Page 2 (01/18/08) } \\
\hline & Calibrat or and Te mperature & 80i 5-min avg, $\mu \mathrm{g} / \mathrm{m} 3$ & Nested Ratio \\
\hline 1 & Thermo03 81i, ambient & 14.71 & \\
\hline 2 & Thermo02 $81 \mathrm{i}, 10^{\circ} \mathrm{C}$ & 13.68 & 0.931 \\
\hline 3 & Thermo03 81i, ambient & 14.68 & \\
\hline \multicolumn{4}{|c|}{$10^{\circ} \mathrm{C}, 30.00 \mu \mathrm{g} / \mathrm{m} 3 \mathrm{Nominal}$} \\
\hline \multicolumn{4}{|c|}{ Refe rence Rovani WRI Notebook 1241 Page 2 (01/18/08) } \\
\hline & Calibrator and Temperature & $80 \mathrm{i} 5-\mathrm{min}$ avg,$\mu \mathrm{g} / \mathrm{m} 3$ & Nested Ratio \\
\hline 1 & Thermo03 81i, ambient & 30.09 & \\
\hline 2 & Thermo02 $81 \mathrm{i}, 10^{\circ} \mathrm{C}$ & 23.88 & 0.796 \\
\hline 3 & Thermo03 81i, ambient & 29.88 & \\
\hline 4 & Thermo02 $81 \mathrm{i}, 10^{\circ} \mathrm{C}$ & 23.95 & 0.803 \\
\hline 5 & Thermo03 81i, ambient & 29.77 & \\
\hline 6 & Thermo02 $81 \mathrm{i}, 10^{\circ} \mathrm{C}$ & 23.99 & 0.807 \\
\hline 7 & Thermo03 81i, ambient & 29.67 & \\
\hline
\end{tabular}




\section{Effect of Ambient Pressure on Calibrator Output}

To investigate the effect of ambient pressure on the calibrators, a new 55-gallon stainless steel drum with sealable lid was utilized as a pressure chamber. Photos of the pressure chamber are shown in Figure 8.
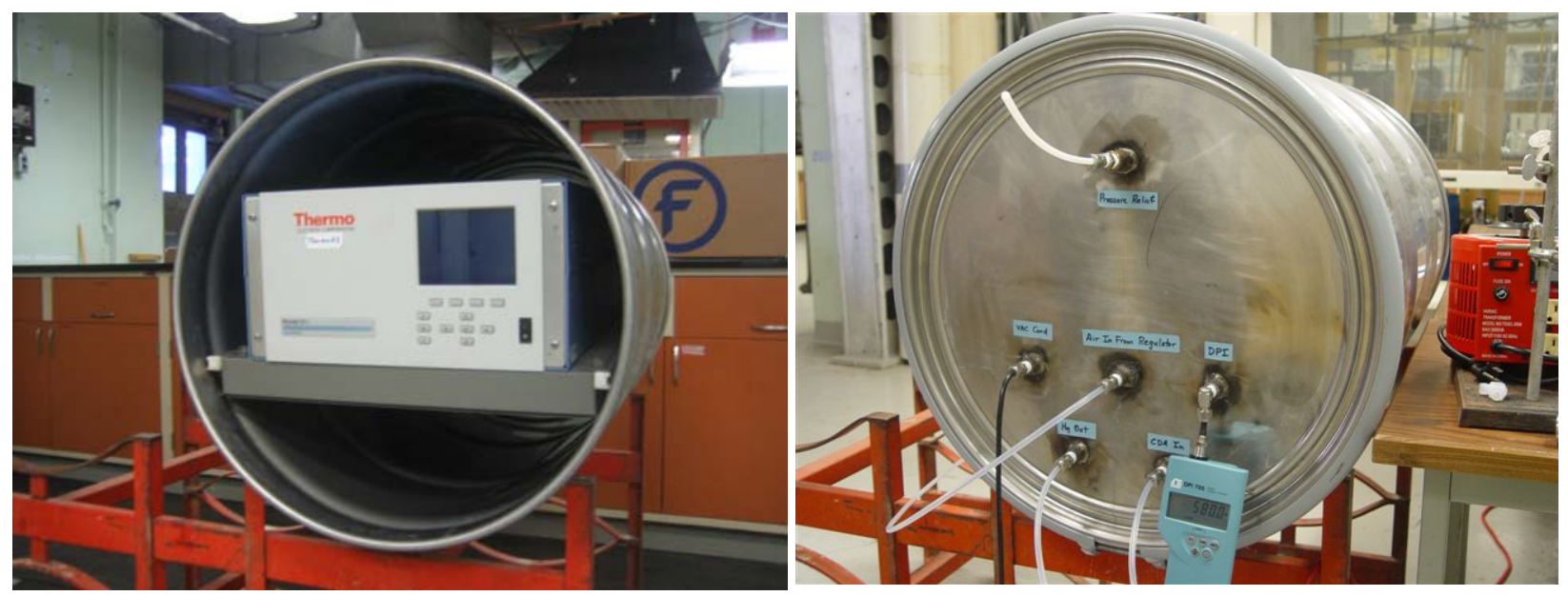

Figure 8. Ambient Pressure Chamber

The six ports welded into the lid include a pressure relief valve (top), electrical cord (mid left), PFA line from a compressed air cylinder for chamber pressurization (center), digital pressure indicator (mid right), PFA Hg output line to the analyzer (bottom left), and PFA clean dry air (CDA, bottom right) inlet to the calibrator in the chamber. The Thermo 02 calibrator was placed inside the drum, the lid was sealed, and the calibrator was operated at ambient pressure and two hyperbaric conditions. The ambient barometric pressure in Laramie, WY is 0.78 atm, which served as the control pressure. The two hyperbaric conditions used were 0.95 atm and 1.1 atm. For operating such a chamber at sea level, a mild vacuum can be applied to simulate high atmosphere conditions. The experimental sequence used was an inter-unit sequence in which the test calibrator was operated at $0.78,0.95$, and 1.1 atm with a return to 0.78 atm. Meanwhile, the Thermo 03 control calibrator was operated at 0.78 atm on an adjacent lab bench outside of the ambient pressure chamber. The effect on the elemental mercury concentration delivered by the calibrators was evaluated at three nominal concentration settings. Eight-minute intervals were used between readings. As with all other testing described in this report, 5-minute averages were used for the $80 \mathrm{i}$ analyzer results.

The modified atmospheric pressure was applied only to the calibrator unit itself, and not to the inlet or outlines for air and calibration gas flow. The back pressure variability was evaluated in a different set of experiments described earlier. Results for concentrations of 5, 15, 
and $30 \mathrm{ug} / \mathrm{m}^{3}$ are presented in Tables 12,13 , and 14 for the Thermo 02 unit nested against the Thermo 03 unit at 5,15 , and $30 \mu \mathrm{g} / \mathrm{m}^{3}$, respectively.

Table 12. Ambient Pressure Variation Data for Thermo 02 Calibrator at $5 \mu \mathrm{g} / \mathrm{m}^{3}$

\begin{tabular}{|c|c|c|c|c|}
\hline $\begin{array}{l}5 \mu \mathrm{g} / \mathrm{m} 3 \mathrm{Nominal} \mathrm{S} \\
\text { Sequence }\end{array}$ & $\mathrm{g}, \mathrm{mmHg}$ & $\mathrm{P}$, atm & $80 \mathrm{i} \mu \mathrm{g} / \mathrm{m} 3$ & Nested Ratio \\
\hline Thermo03 ambient & & & 4.63 & \\
\hline Thermo02 ambient & 587.6 & 0.7732 & 4.49 & 0.9729 \\
\hline Thermo03 ambient & & & 4.60 & \\
\hline Thermo02 ambient & 588.6 & 0.7745 & 4.47 & 0.9696 \\
\hline Thermo03 ambient & & & 4.62 & \\
\hline Thermo02 ambient & 589.5 & 0.7757 & 4.47 & 0.9686 \\
\hline Thermo03 ambient & & & 4.61 & \\
\hline Thermo03 ambient & & & 4.61 & \\
\hline Thermo02 0.95 atm & 728.4 & 0.9584 & 4.49 & 0.9740 \\
\hline Thermo03 ambient & & & 4.61 & \\
\hline Thermo02 $0.95 \mathrm{~atm}$ & 721.3 & 0.9491 & 4.48 & 0.9718 \\
\hline Thermo03 ambient & & & 4.61 & \\
\hline Thermo02 $0.95 \mathrm{~atm}$ & 728.6 & 0.9587 & 4.49 & 0.9740 \\
\hline Thermo03 ambient & & & 4.61 & \\
\hline Thermo03 ambient & & & 4.61 & \\
\hline Thermo02 $1.1 \mathrm{~atm}$ & 825.7 & 1.0864 & 4.49 & 0.9750 \\
\hline Thermo03 ambient & & & 4.60 & \\
\hline Thermo02 $1.1 \mathrm{~atm}$ & 825.6 & 1.0863 & 4.48 & 0.9729 \\
\hline Thermo03 ambient & & & 4.61 & \\
\hline Thermo02 $1.1 \mathrm{~atm}$ & 825.7 & 1.0864 & 4.49 & 0.9740 \\
\hline Thermo03 ambient & & & 4.61 & \\
\hline Thermo03 ambient & & & 4.60 & \\
\hline Thermo02 ambient & 592.7 & 0.7799 & 4.41 & 0.9587 \\
\hline Thermo03 ambient & & & 4.60 & \\
\hline Thermo02 ambient & 593.2 & 0.7805 & 4.41 & 0.9587 \\
\hline Thermo03 ambient & & & 4.60 & \\
\hline Thermo02 ambient & 593.5 & 0.7809 & 4.41 & 0.9587 \\
\hline Thermo03 ambient & & & 4.60 & \\
\hline
\end{tabular}


Table 13. Ambient Pressure Variation Data for Thermo 02 Calibrator at $15 \mu \mathrm{g} / \mathrm{m}^{3}$

\begin{tabular}{|c|c|c|c|c|}
\hline \\
\hline \multicolumn{2}{|c|}{ Sequence $\quad P, \mathrm{mmHg}$} & \multirow[t]{2}{*}{$P$, atm } & \multirow{2}{*}{$\begin{array}{r}80 \mathrm{i} \mu \mathrm{g} / \mathrm{m} 3 \\
14.38\end{array}$} & \multirow[t]{2}{*}{ Nested Ratio } \\
\hline Thermo03 ambient & & & & \\
\hline Thermo02 ambient & 584.8 & 0.7695 & 13.52 & 0.9412 \\
\hline Thermo03 ambient & & & 14.35 & \\
\hline Thermo02 ambient & 586.3 & 0.7714 & 13.49 & 0.9404 \\
\hline Thermo03 ambient & & & 14.34 & \\
\hline Thermo02 ambient & 587.6 & 0.7732 & 13.48 & 0.9404 \\
\hline Thermo03 ambient & & & 14.33 & \\
\hline Thermo03 ambient & & & 14.31 & \\
\hline Thermo02 $0.95 \mathrm{~atm}$ & 719.7 & 0.9470 & 13.54 & 0.9462 \\
\hline Thermo03 ambient & & & 14.31 & \\
\hline Thermo02 $0.95 \mathrm{~atm}$ & 719.6 & 0.9468 & 13.52 & 0.9448 \\
\hline Thermo03 ambient & & & 14.31 & \\
\hline Thermo02 $0.95 \mathrm{~atm}$ & 723.0 & 0.9513 & 13.52 & 0.9455 \\
\hline Thermo03 ambient & & & 14.29 & \\
\hline Thermo03 ambient & & & 14.27 & \\
\hline Thermo02 $1.1 \mathrm{~atm}$ & 826.4 & 1.0874 & 13.57 & 0.9509 \\
\hline Thermo03 ambient & & & 14.27 & \\
\hline Thermo02 $1.1 \mathrm{~atm}$ & 830.7 & 1.0930 & 13.56 & 0.9506 \\
\hline Thermo03 ambient & & & 14.26 & \\
\hline Thermo02 $1.1 \mathrm{~atm}$ & 830.2 & 1.0924 & 13.55 & 0.9505 \\
\hline Thermo03 ambient & & & 14.25 & \\
\hline Thermo03 ambient & & & 14.26 & \\
\hline Thermo02 ambient & 580.9 & 0.7643 & 13.38 & 0.9393 \\
\hline Thermo03 ambient & & & 14.23 & \\
\hline Thermo02 ambient & 581.9 & 0.7657 & 13.37 & 0.9392 \\
\hline Thermo03 ambient & & & 14.24 & \\
\hline Thermo02 ambient & 582.8 & 0.7668 & 13.34 & 0.9365 \\
\hline Thermo03 ambient & & & 14.25 & \\
\hline
\end{tabular}


Table 14. Ambient Pressure Variation Data for Thermo 02 Calibrator at $30 \mu \mathrm{g} / \mathrm{m}^{3}$

\begin{tabular}{|c|c|c|c|c|}
\hline \\
\hline \multicolumn{2}{|c|}{$\begin{array}{ll}\text { Sequence } & \mathrm{P}, \mathrm{mmHg}\end{array}$} & \multirow[t]{2}{*}{$P$, atm } & \multirow{2}{*}{$\begin{array}{r}80 \mathrm{i} \mu \mathrm{g} / \mathrm{m} 3 \\
28.99\end{array}$} & \multirow[t]{2}{*}{ Nested Ratio } \\
\hline Thermo03 ambient & & & & \\
\hline Thermo02 ambient & 592.0 & 0.7789 & 26.99 & 0.9323 \\
\hline Thermo03 ambient & & & 28.91 & \\
\hline Thermo02 ambient & 593.9 & 0.7814 & 26.92 & 0.9325 \\
\hline Thermo03 ambient & & & 28.83 & \\
\hline Thermo02 ambient & 595.3 & 0.7833 & 26.87 & 0.9330 \\
\hline Thermo03 ambient & & & 28.77 & \\
\hline Thermo03 ambient & & & 28.65 & \\
\hline Thermo02 $0.95 \mathrm{~atm}$ & 727.9 & 0.9578 & 26.93 & 0.9414 \\
\hline Thermo03 ambient & & & 28.56 & \\
\hline Thermo02 $0.95 \mathrm{~atm}$ & 724.4 & 0.9532 & 26.90 & 0.9422 \\
\hline Thermo03 ambient & & & 28.54 & \\
\hline Thermo02 $0.95 \mathrm{~atm}$ & 721.3 & 0.9491 & 26.85 & 0.9406 \\
\hline Thermo03 ambient & & & 28.55 & \\
\hline Thermo03 ambient & & & 28.39 & \\
\hline Thermo02 $1.1 \mathrm{~atm}$ & 829.8 & 1.0918 & 26.74 & 0.9420 \\
\hline Thermo03 ambient & & & 28.38 & \\
\hline Thermo02 $1.1 \mathrm{~atm}$ & 827.8 & 1.0892 & 26.71 & 0.9418 \\
\hline Thermo03 ambient & & & 28.34 & \\
\hline Thermo02 $1.1 \mathrm{~atm}$ & 830.1 & 1.0922 & 26.64 & 0.9400 \\
\hline Thermo03 ambient & & & 28.34 & \\
\hline Thermo03 ambient & & & 28.32 & \\
\hline Thermo02 ambient & 587.2 & 0.7726 & 26.27 & 0.9279 \\
\hline Thermo03 ambient & & & 28.30 & \\
\hline Thermo02 ambient & 588.2 & 0.7739 & 26.25 & 0.9281 \\
\hline Thermo03 ambient & & & 28.27 & \\
\hline Thermo02 ambient & 589.0 & 0.7750 & 26.27 & 0.9288 \\
\hline Thermo03 ambient & & & 28.30 & \\
\hline
\end{tabular}

Overall, the results show minimal dependence of output concentration on ambient pressures ranging from 0.78 to 1.1 atmospheres in the nested ratios for the Thermo 02 calibrator unit, indicating that the effect of ambient pressure on the unit itself is negligible. However, at some point it might be useful to gauge the effects, if any, of the entire calibrator/spectrometer system.

\section{OXIDIZED MERCURY GENERATOR CONVERSION EFFICIENCY}

The mercury emissions from coal-fired power plants are comprised of both elemental and oxidized mercury. Current CEMs are designed to measure elemental mercury at a probe in the power plant emission stack. Oxidized mercury must first be converted to elemental mercury before the probe in order to be measured using existing CEM technology. For regulatory purposes, mercury $(\mathrm{Hg})$ calibration standards of known concentration and known uncertainty are needed to quality-assure data recorded by $\mathrm{Hg}$ CEMs. There are currently two basic types of 
mercuric chloride $\left(\mathrm{HgCl}_{2}\right)$ generators used for this purpose. One is an evaporative $\mathrm{HgCl}_{2}$ generator, which produces gas standards of known concentration by vaporization of aqueous $\mathrm{HgCl}_{2}$ solutions and quantitative mixing with a diluent carrier gas. The other is a device that converts the output from an elemental $\mathrm{Hg}$ generator to $\mathrm{HgCl}_{2}$ by means of a chemical reaction with chlorine gas. The Thermo Fisher configuration generates mercuric chloride gas at the stack sampling location utilizing a reaction between elemental mercury from an elemental mercury calibrator and chlorine gas. Reduction back to elemental, mercury occurs in a high temperature reaction chamber adjacent tot the oxidation chamber

Acting as a third party, WRI worked closely with Thermo Fisher Scientific to determine the efficiency of oxidation and reduction of a stand alone mercury oxidation unit that converts elemental mercury to mercuric chloride using a reaction of elemental mercury with chlorine gas. In particular, the work below is to show the interlaboratory reproducibility of efficiency of oxidation and reduction of a mercury gas stream using a stand alone unit.

\section{$\underline{\text { Initial Experiment }}$}

An initial experiment with the stand-alone Thermo oxidized mercury generator (SAOX) was conducted using the Thermo $0480 \mathrm{i}$ elemental mercury calibrator set at $5.7 \mu \mathrm{g} / \mathrm{m}^{3}$ as the elemental mercury vapor source and a Thermo 80i Mercury Analyzer. A photograph of the SAOX unit is provided in Figure 9.

Initially, the $81 \mathrm{i}$ was connected to the hydrator on the SAOX and the power was turned on. Temperatures of $760{ }^{\circ} \mathrm{C}$ and $400{ }^{\circ} \mathrm{C}$ were recorded for the reducing and oxidizing chambers, respectively. The $80 \mathrm{i}$ analyzer was then calibrated at mercury levels of 0 and $5.7 \mu \mathrm{g} / \mathrm{m}^{3}$ from the $81 \mathrm{i}$ calibrator. A flow of $900 \mathrm{ppm}$ chlorine in nitrogen gas was established at $75 \mathrm{cc} / \mathrm{min}$ using a bubble meter. Next, a sequence was started in the SAOX that involved flipping the toggle switch labeled sequence.

At the beginning of the sequence the cal gas was only flowing from the sample dump outlet of the SAOX system and the level of elemental mercury, as measured by the analyzer, was recorded up to the seventeen minute point to be 5.5926 for a five minute average. At this setting the calibrator output flow is about $12 \mathrm{~L} / \mathrm{min}$. (Table 3). It's interesting to note that flows from the sample dump, $\operatorname{Hg}(0)$ out and $\mathrm{HgT}$ out were monitored throughout the experiment, but gas was only exiting through the sample dump. 


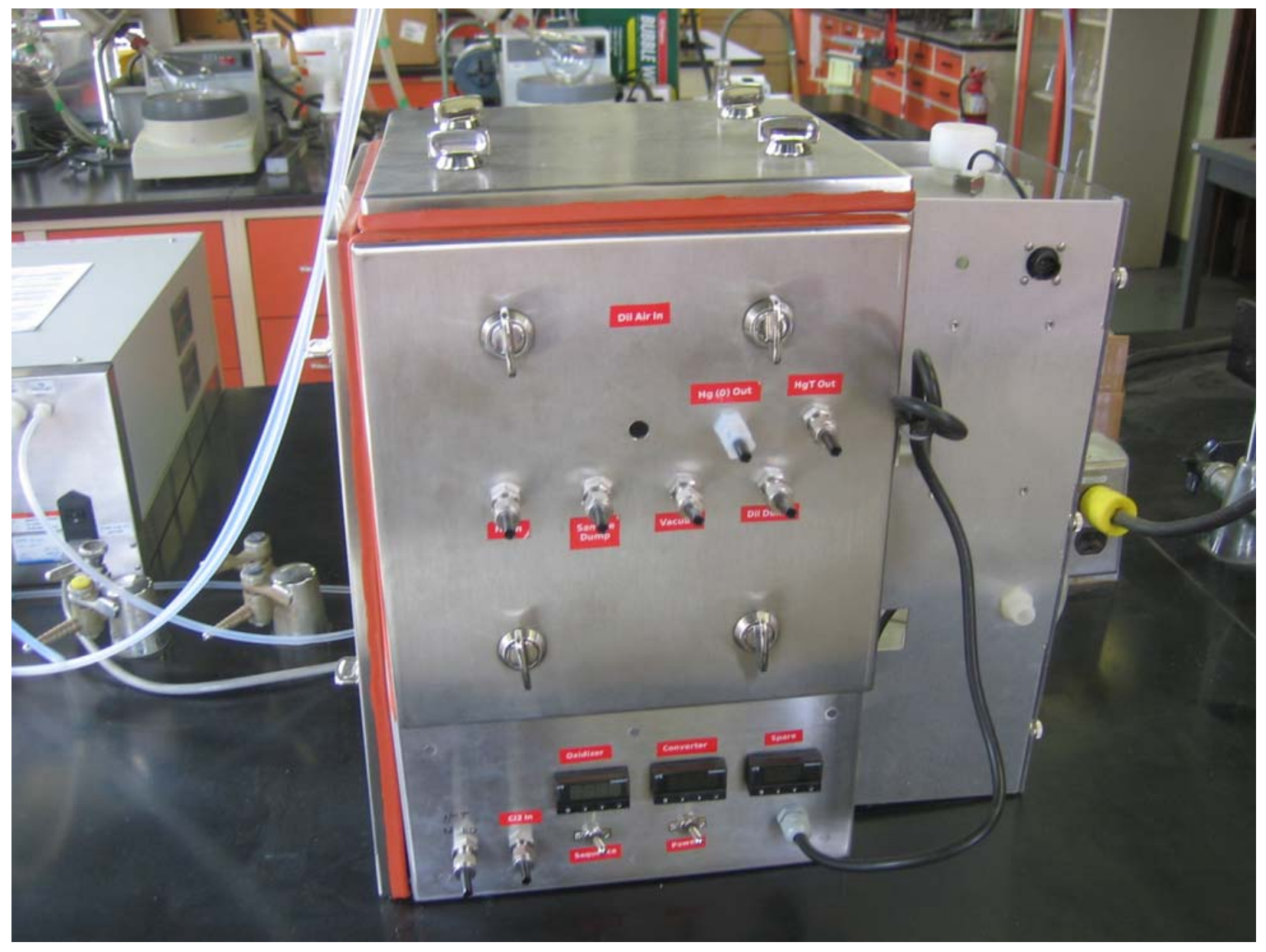

Figure 9. Thermo Fisher Stand-alone Oxidizer Unit

At the seventeen minute point of the sequence the automated solenoid chlorine valve was heard to open and a drop in mercury concentration was expected. However, after approximately four minutes no appreciable change was observed as can be seen in Table 14. In the column marked "Before Bumping Cl" the $80 \mathrm{i}$ was reading a concentration of $5.593 \mu \mathrm{g} / \mathrm{m}^{3}$ after four minutes of supposed chlorine gas exposure. It is believed that no chlorine was being introduced into the oxidation chamber. There was no audible flow from the regulator supplied by Thermo at $\sim$ 1psi. Additionally, when calibrating the flow using the bubble meter the regulator was very "touchy", meaning that the presence of back pressure or simply touching the adjuster could have rendered a flow stoppage. After the four minutes of no change in concentration at the analyzer the chlorine gas regulator was adjusted to between 2 and 3 psi, at which time an audible flow was noted. The $\mathrm{Hg}$ concentration at the analyzer immediately dropped to $1.04 \mu \mathrm{g} / \mathrm{m}^{3}$ (Table 15). 
Table 15: Elemental Mercury Measurements at Key Points of the Initial Experiment.

\begin{tabular}{|c|c|c|c|}
\hline$\underline{\text { Measurement Time }}$ & $\begin{array}{l}\text { 81i Set } \\
\text { Output }\end{array}$ & $\begin{array}{l}80 \mathrm{i} \\
\text { Actual }\end{array}$ & $\begin{array}{l}\text { Sampling } \\
\text { Time }\end{array}$ \\
\hline Reading During Sequence Before Chlorine Flow & 5.7 & 5.5926 & $\begin{array}{l}5 \text { minute } \\
\text { average }\end{array}$ \\
\hline Reading Before Bumping $\mathrm{Cl}_{2}$ to $\sim 3$ psi at 13:36 & 5.7 & 5.58627 & $\begin{array}{l}1 \text { minute } \\
\text { average }\end{array}$ \\
\hline Reading After Bumping $\mathrm{Cl}_{2}$ to $\sim 3$ psi at $13: 42$ & 5.7 & 1.044 & $\begin{array}{l}1 \text { minute } \\
\text { average }\end{array}$ \\
\hline Reading After Reducing $\mathrm{Cl}_{2}$ flow back to $<1$ psi at 13:47 & 5.7 & 0.9496 & $\begin{array}{l}4 \text { minute } \\
\text { average }\end{array}$ \\
\hline Reading After Increasing $\mathrm{Cl}_{2}$ flow to $\sim 3$ psi at 13:53 & 5.7 & 0.1792 & $\begin{array}{l}5 \text { minute } \\
\text { average }\end{array}$ \\
\hline Reading Immediately After $\mathrm{Cl}_{2}$ flow stopped at 13:54 & 5.7 & 1.6984 & $\begin{array}{l}1 \text { minute } \\
\text { average }\end{array}$ \\
\hline Reading Average After $\mathrm{Cl}_{2}$ flow stopped at 14:10 & 5.7 & 5.1326 & $\begin{array}{l}5 \text { minute } \\
\text { average }\end{array}$ \\
\hline
\end{tabular}

To ensure that the decrease in elemental mercury output was not due to a dilution of the cal gas, the chlorine gas pressure was returned to a lower level of $\sim 1$ psi. At this point the elemental mercury concentration reported by the analyzer was steady at $0.950 \mu \mathrm{g} / \mathrm{m}^{3}$. If the observed decrease in elemental mercury at the analyzer was due to dilution by a high flow of chlorine gas, a decrease in chlorine gas flow would have resulted in an increase in mercury concentration at the analyzer. However, this was not the case. This coupled with the steady Hg concentration reading indicates that the oxidizer was working efficiently. The chlorine gas flow was then returned to $\sim 3$ psi at which point a five minute average of measurements at the analyzer indicated a decreased $\mathrm{Hg}$ concentration to $0.179 \mu \mathrm{g} / \mathrm{m}^{3}$. This represents a $97 \%$ conversion to oxidized mercury, without corrections for dilution effects.

At the 34 minute mark of the sequence chlorine gas flow was stopped and the analyzer immediately indicated a 12 -fold increase in elemental mercury concentration. It is interesting to note that the sequences before and after the sequence switch is flipped are seventeen rather than fifteen minutes. Finally, after a fifteen minute recovery time, the analyzer indicated a return to $5.133 \mu \mathrm{g} / \mathrm{m}^{3}$. Therefore, the recovery time appears to take more than fifteen minutes. It is also interesting to note that, around the 40 minute mark, the SAOX system no longer accepted gas through the inlet and it was instead vented through the top compartment of the hydrator. This 
problem occurred because of the configuration of the hydrator on the SAOX unit. When the water level in the hydrator chamber drops below a certain level, the float valve opens to the reservoir chamber which then acts as an air dump when air flow is present, preventing flow to the SAOX unit. The initial results indicate that the SAOX system is capable of efficiently oxidizing $\mathrm{Hg}(\mathrm{O})$ to $\mathrm{Hg}(2)$ using chlorine gas. Following the initial experiment, the SAOX unit was returned to Thermo Fisher for some additional modification so that experiments to quantitatively determine the oxidation and reduction efficiencies could be performed.

\section{Quantitative Stand-Alone Oxidizer Procedure}

Following the initial experiment, the quantitative work at WRI was conducted with the modified SAOX unit in a manner similar to the Thermo Fisher Experiment 3 described below. In a Thermo Fisher memo dated November 11, 2008, the results from three different experiments performed at Thermo Fisher Scientific using a stand-alone mercury oxidation system (SAOX) were described. These experiments were performed to demonstrate that oxidation efficiency of the SAOX is severely understated when based on $\mathrm{Hg}^{2+}$ concentrations reported using the difference method. The difference method of measuring $\mathrm{Hg}^{2+}$ concentration is performed by measuring the mercury output of two flow paths from the SAOX, one oxidized and one not. It is common knowledge in the emissions community that conditions such as temperature, pressure, and surface area can affect the apparent reduction efficiency of $\mathrm{HgCl}_{2}$. The three experiments were run as summarized below

Thermo Fisher Experiment 1: $\quad \mathrm{An} \mathrm{HgCl}_{2}$ generator was coupled to a set of three impingers, two filled with water and one empty. The impinger train was fed to a set of orifices downstream from an atmospheric dump that controlled the pressure and flow rate of both sample channels of the downstream analyzer. $\mathrm{The} \mathrm{Hg}(\mathrm{T})$ channel was fed by a $\mathrm{HgCl}_{2}$ converter while the $\mathrm{Hg}(0)$ channel went directly to the analyzer. The $\mathrm{HgCl}_{2}$ converter was designed to reduce the oxidized $\mathrm{Hg}$ back to elemental $\mathrm{Hg}$. Both probe and system components were removed to reduce surface area and temperature of the sample path. Water impingers were used to capture all of the $\mathrm{HgCl}_{2}$ generated and to eliminate any downstream reduction into elemental mercury. Any $\mathrm{Hg}(0)$, being insoluble in water, would register in both the $\mathrm{Hg}(0)$ and $\mathrm{Hg}(\mathrm{T})$ channel at the CEM. Initially, the impinger train was bypassed while the setup was zeroed and spanned and then added in series with the outlet of the oxidizer while zero and span gas were passed through the system. After several minutes, chlorine flow was initiated into the oxidizer, followed by an oxidizer purge with zero air. The oxidation efficiency as measured by the $\operatorname{Hg}(0)$ channel, was 99.8\%. $\mathrm{Hg}(\mathrm{t})$ measurements were very low, as expected, since most of the $\mathrm{HgCl}_{2}$ was trapped in the water impingers. Experiments 2 and 3 below were subsequently run to eliminate the impingers as an oxidation source. 
Thermo Fisher Experiment 2: $\quad$ This experiment was run identically to experiment one except that the impinger train was removed. The setup was zeroed and spanned, subjected to zero and span gas for several minutes, and chlorine flow was initiated in the oxidizer. This time the oxidation efficiency was $98.3 \%$ as measured by the $\operatorname{Hg}(0)$ channel. Low total efficiency (system integrity) was observed for the experiment, $80.6 \%$, as determined by the $\operatorname{Hg}(\mathrm{T})$ measurements. This was not unexpected and most likely due to the lack of heat tracing which resulted in the loss of $\mathrm{HgCl}_{2}$ before the converter (reducing chamber). Experiment 3 was performed to demonstrate that the apparent poor total efficiency was a result of $\mathrm{HgCl}_{2}$ adsorption in Experiment 2.

Thermo Fisher Experiment 3: $\quad$ The test setup for this experiment was identical to Experiment 2 with the addition of a heat trace (insulation) to the output of the oxidizer and the orifice assembly to maintain a temperature of approximately $150{ }^{\circ} \mathrm{C}$ in the line. The setup was zeroed and spanned, subjected to zero and span gas for several minutes, and chlorine flow was initiated in the oxidizer. Oxidation efficiency decreased to $94.4 \%$, however the subsequent conversion efficiency (reduction) was $101.8 \%$. This shows that the heat trace prevented $\mathrm{HgCl}_{2}$ from adsorbing upstream of the converter. The decrease in oxidation efficiency from experiment 2 was attributed to an increased sample temperature and enhanced $\mathrm{HgCl}_{2}$ reduction on apparatus surfaces.

The modified prototype SAOX unit supplied to WRI by Thermo Fisher differs from the unit used at Thermo Fisher in the above Experiments 1-3 in several areas. First, the WRI SAOX Oxidation and Reduction/Conversion chambers are both within the same box. In the Thermo Fisher experiments above, the conversion unit was placed downstream from the oxidizer. Second, the chlorine flow for the WRI unit was controlled using a regulator on the chlorine gas cylinder and an in-line flow meter. An orifice was used to control the flow of chlorine in the Thermo Fisher experiments above. The flow diagram in Figure 10 provides a good description of the overall experimental setup. Mercury in air elemental calibration gas flow is supplied by a Thermo 81i calibrator. The elemental calibration gas flow is directed through a hydrating chamber where it flows over standing water and into the SAOX apparatus. Chlorine gas $(900$ ppm in nitrogen) is supplied by a compressed gas cylinder where flow is determined by a regulator setting and measured with a flow meter to run at $400 \mathrm{~mL} / \mathrm{min}$ nominal gas flow. In the SAOX gases are first sent through an oxidation chamber at $400{ }^{\circ} \mathrm{F}$ after which flow is split between the $\operatorname{Hg}(0)$ outlet, a line to the reduction chamber, or an atmospheric dump. The line from the reducing chamber exits the SAOX system through the $\mathrm{Hg}(\mathrm{t})$ outlet. Two critical orifices can be found in the SAOX at the exits of the oxidation and reduction chambers that regulate flow and back pressure at the analyzer. Both the $\operatorname{Hg}(\mathrm{T})$ and $\operatorname{Hg}(0)$ outlets from the SAOX are run to the matching inlets on the back of the Thermo 80i analyzer. The analyzer software is set to system span and auto $\mathrm{Hg}(\mathrm{T}) / \mathrm{Hg}(0)$. In this mode, the analyzer alternates readings between the two inlets on the back of the instrument each minute. This makes it possible to measure the efficiency of both the oxidation as well as the reduction simultaneously. 


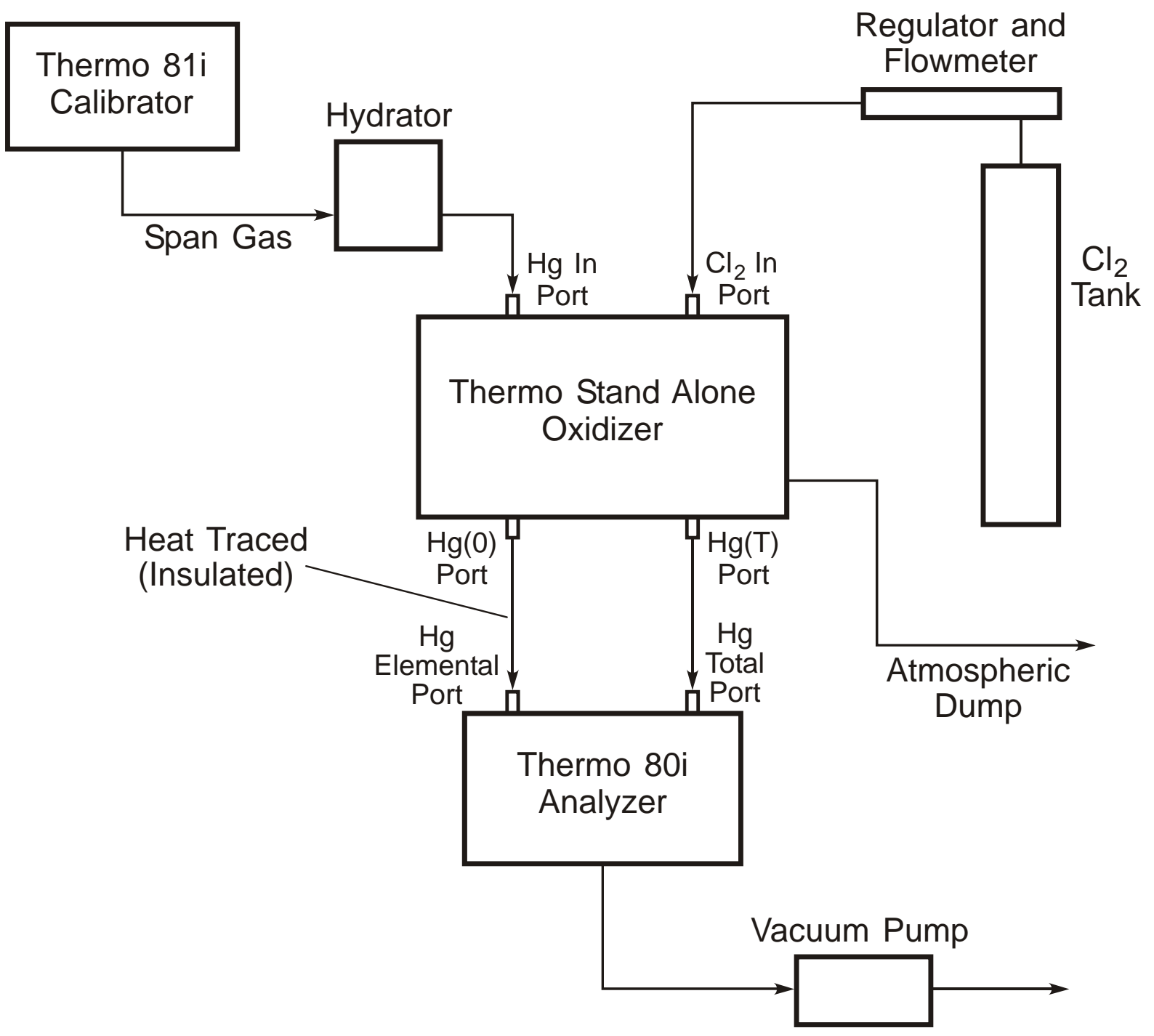

Figure 10. Schematic of the Experimental Setup for SAOX Testing.

\section{WRI Conversion Efficiency Experiments}

The experiments performed at WRI were based on the Thermo Fisher Experiment 3 conditions described above. Before starting, the SAOX was allowed to "warm up" to display a steady temperature reading in both the oxidation and reduction chambers. This usually required about 20 minutes. Once this has been completed the typical experiment begins by zeroing and spanning the analyzer through the apparatus at a mercury concentration of $9.5 \mu \mathrm{g} / \mathrm{m}^{3}$. Once stable readings have been obtained gas flow is maintained with a nominal concentration of 9.5 $\mu \mathrm{g} / \mathrm{m}^{3}$ of mercury and the "sequence" switch is toggled on the front of the SAOX to begin the oxidation process. Though times varied, typically gas flow was maintained by the system for 
about 20 minutes at which time the chlorine flow began. As mentioned above, $\mathrm{Cl}_{2}$ flow was maintained at $400 \mathrm{~mL} / \mathrm{min}$ and was signaled by a faint click in the SAOX or observed by a drop in concentration in the $\operatorname{Hg}(0)$ channel. Chlorine flow was maintained for approximately 20 minutes and alternating $\operatorname{Hg}(\mathrm{T})$ and $\operatorname{Hg}(0)$ measurements were recorded by the analyzer. After chlorine flow was halted, as determined by change in $\operatorname{Hg}(0)$ concentration, the instrument was allowed to flow for 15 minutes at $9.5 \mu \mathrm{g} / \mathrm{m}^{3}$ and then purged for 30 minutes with zero air before another experiment was performed.

A number of equations provided by Thermo Fisher are presented below. These include a dilution factor, adjusted observed baseline corrections for $\mathrm{Hg}(0)$ and $\mathrm{Hg}(\mathrm{T})$, and the efficiencies for both the oxidation and reduction processes. The dilution factor is based on the effect of the chlorine gas flow on the concentration of mercury in the flow from the $81 \mathrm{i}$ calibrator and is shown in Equation 1.

$$
D F=\frac{81 \text { flow }+\mathrm{Cl}_{2} \text { flow }}{81 \text { flow }}
$$

Adjusted oxidized baselines are calculated based on the chlorine dilution factor (DF). The adjusted oxidizer baseline for the $\mathrm{Hg}(\mathrm{T})$ channel is termed $\mathrm{AOB}(\mathrm{T})$ and shown in Equation 2. $\mathrm{Hg}(\mathrm{T}) \mathrm{X}$ is the $\mathrm{Hg}(\mathrm{T})$ concentration measured at the analyzer at the end of the oxidizer baseline.

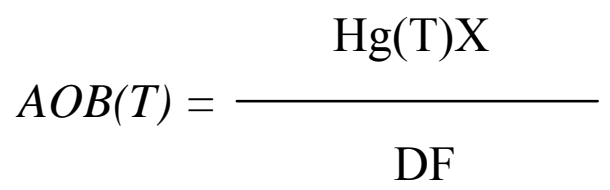

The adjusted baseline for the $\operatorname{Hg}(0)$ channel is represented by $\operatorname{AOB}(0)$ and shown in Equation 3 . $\mathrm{Hg}(0) \mathrm{X}$ is the $\operatorname{Hg}(0)$ concentration measured at the analyzer at the end of the oxidizer baseline.

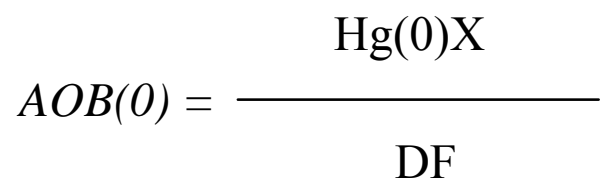

Once the adjusted oxidizer baselines have been calculated those numbers can be used to calculate the efficiency of each process. The oxidizer efficiency $O E$ for the SAOX can be calculated as shown in Equation 4 where the $\operatorname{Hg}(0) \mathrm{Y}$ is the $\operatorname{Hg}(0)$ concentration as measured by the analyzer at the end of the chlorine duration. 


$$
O E=\frac{\operatorname{Hg}(0) Y}{\operatorname{AOB}(0)} * 100
$$

The total efficiency (TE) for the process of elemental mercury oxidation to $\mathrm{HgCl}_{2}$ and reduction back to elemental mercury by the SAOX can be calculated as shown in equation 5. Here $\operatorname{Hg}(\mathrm{T}) \mathrm{Y}$ is the $\operatorname{Hg}(\mathrm{T})$ concentration as measured by the analyzer at the end of the chlorine duration.

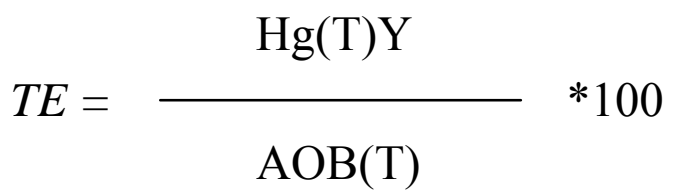

Three replicate conversion efficiency experiments were conducted at separate times. Graphical results for each trial are shown below.

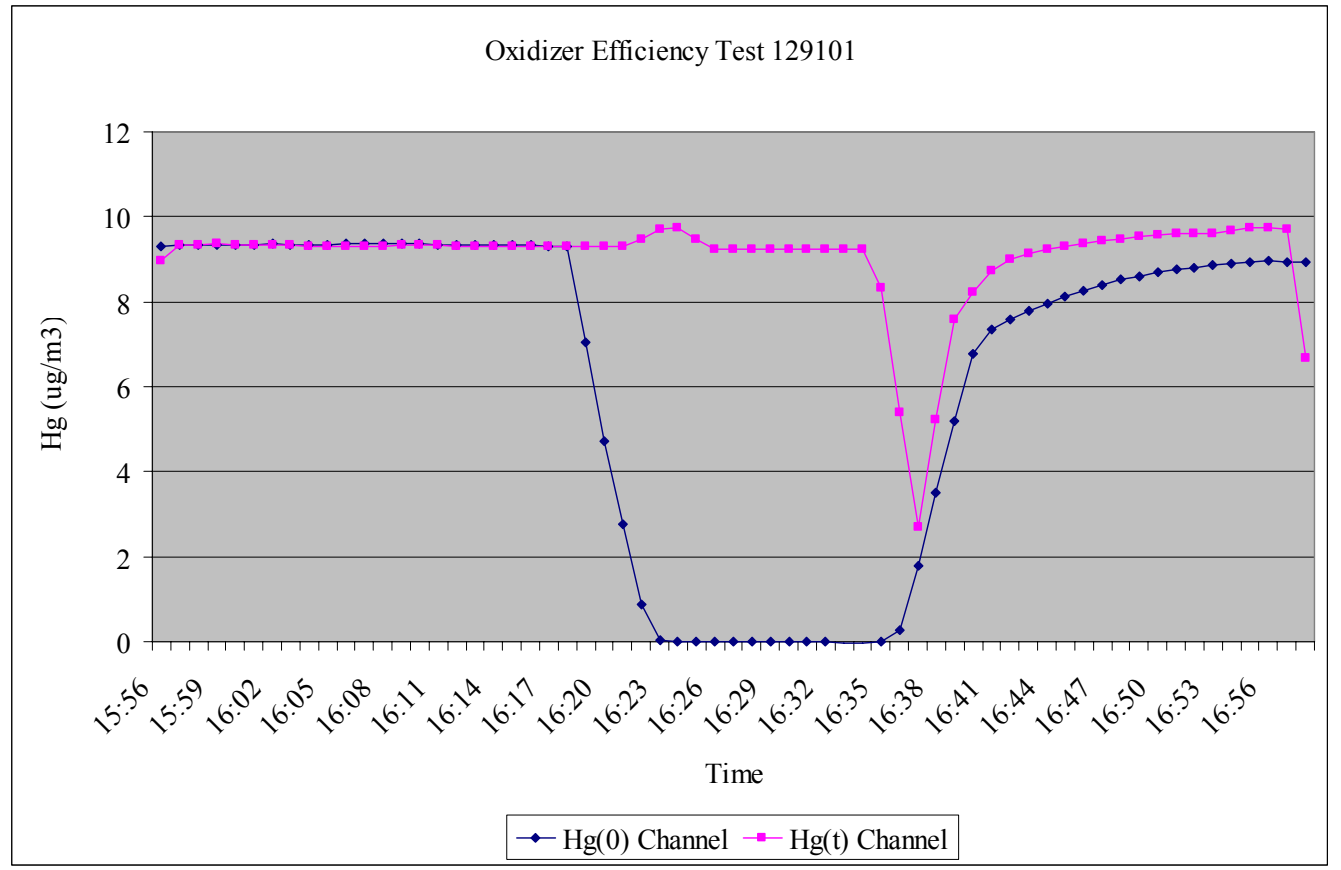

Figure 11. Results from SAOX Efficiency Experiment 129101 
A dilution factor of 1.054 was determined for experiment 129101. Using the dilution factor the adjusted oxidizer baselines were calculated. $\mathrm{AOB}(\mathrm{T})$ was calculated to be $8.83 \mu \mathrm{g} / \mathrm{m}^{3}$ and $\mathrm{AOB}(0)$ was 8.84 . The efficiency of oxidation was $100.2 \%$ and the total efficiency of the system, both oxidized and reduced, was $104.5 \%$.

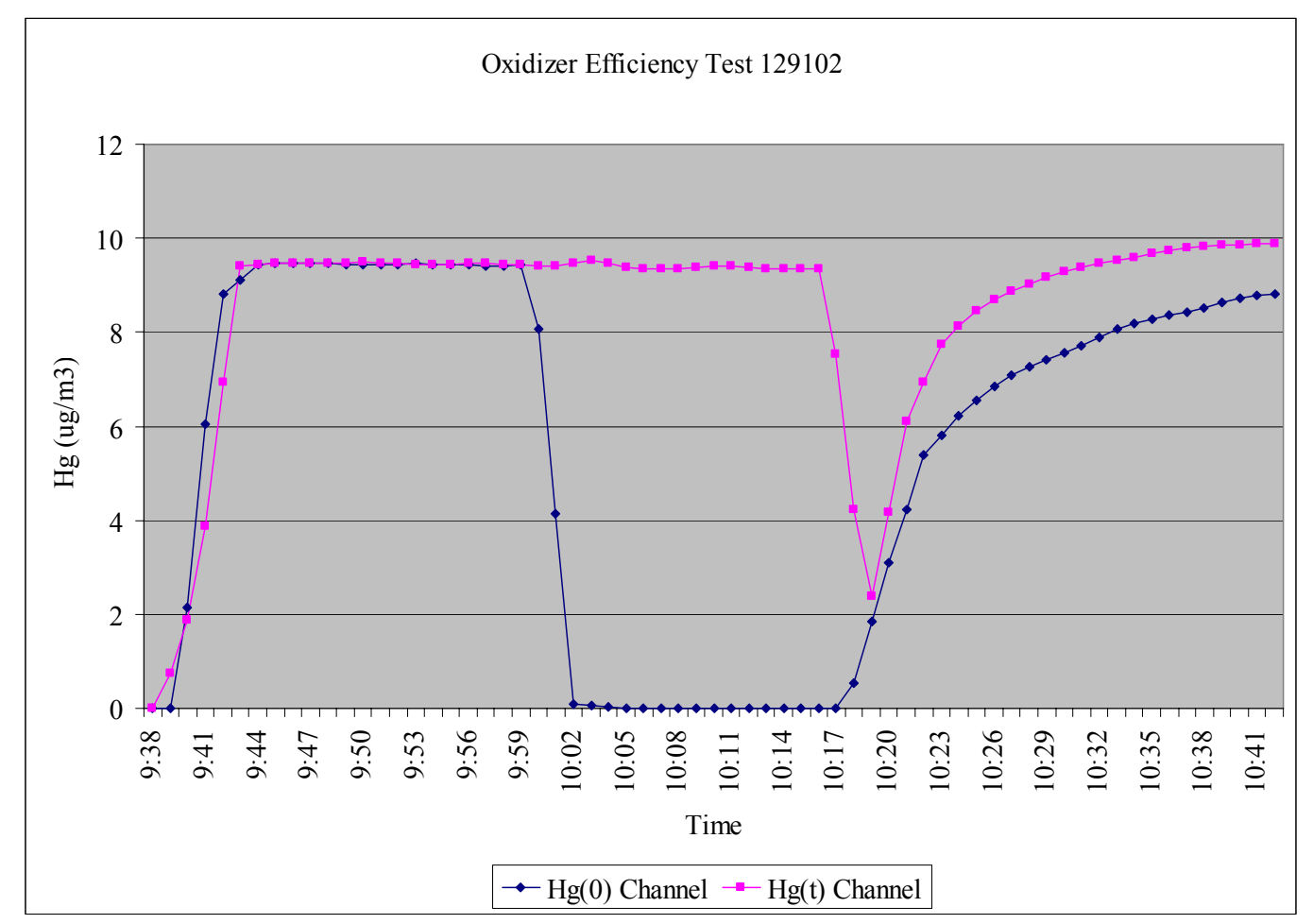

Figure 12. Results from SAOX Efficiency Experiment 129102

A dilution factor of 1.054 was determined for experiment 129102. Using the dilution factor the adjusted oxidizer baselines were calculated. $\mathrm{AOB}(\mathrm{T})$ was calculated to be $8.96 \mu \mathrm{g} / \mathrm{m}^{3}$ and $\mathrm{AOB}(0)$ was 8.95 . The efficiency of oxidation was $100.1 \%$ and the total efficiency of the system, both oxidized and reduced, was $104.6 \%$. 


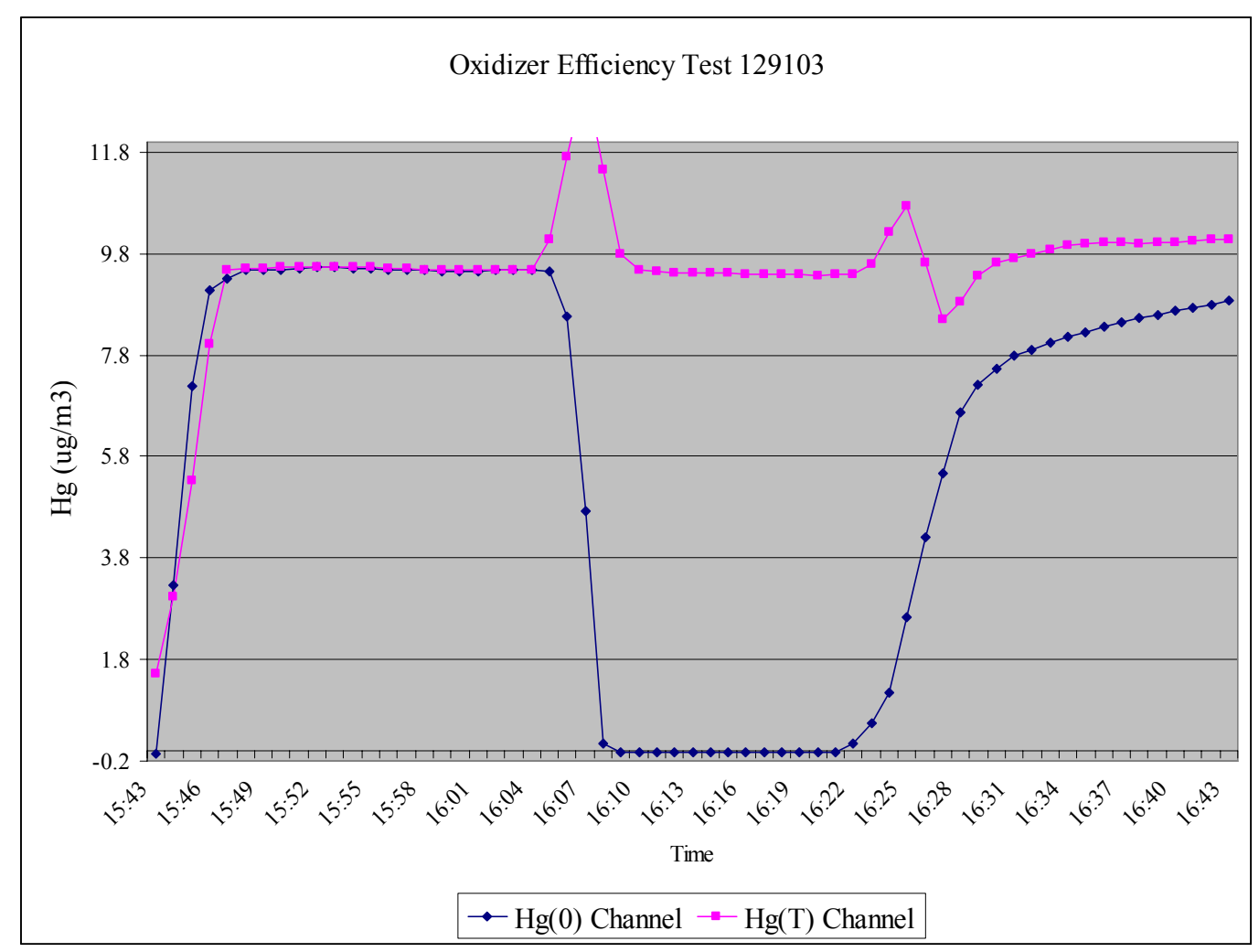

Figure 13. Results from SAOX Efficiency Experiment 129103

A dilution factor of 1.054 was determined for experiment 129103. Using the dilution factor the adjusted oxidizer baselines were calculated. AOB(T) was calculated to be $8.99 \mu \mathrm{g} / \mathrm{m}^{3}$ and $\mathrm{AOB}(0)$ was 9.00 . The efficiency of oxidation was $100.1 \%$ and the total efficiency of the system, both oxidized and reduced, was $104.3 \%$.

\section{SAOX Efficiency Results}

For each of the three experiments the identical dilution factor of 1.054 was calculated, very similar to the 1.058 found in the Thermo Fisher experiments. Considering what factors into the DF calculation this merely indicates that the relative $81 \mathrm{i}$ flows from the two sets of experiments were similar. The chlorine dilution flow of $400 \mathrm{~mL} / \mathrm{min}$ for the two sets of experiments is the same, though it is important to reiterate that the flows were measured differently. In the Thermo Fisher experiments a critical orifice was in place on the $\mathrm{HgCl}_{2}$ generator while the regulator was used to control the chlorine flow and a flow meter to measure it for these experiments. Depending on the actual chlorine flow through the critical orifice in the Thermo Fisher experiments this could be a source for the minor discrepancies observed in the data between the two experimental sets. 
The adjusted oxidizer baselines agreed well for the three experiments above. The AOB for the $\mathrm{Hg}(\mathrm{T})$ line ranged from 8.83 to $8.99 \mu \mathrm{g} / \mathrm{m}^{3}$, about a $2 \%$ difference, which indicates good repeatability from one experiment to another. The AOB for the $\mathrm{Hg}(0)$ line ranged from 8.84 to 9 $\mu \mathrm{g} / \mathrm{m}^{3}$ which not only indicates good repeatability within the experimental set but also indicates that the $\mathrm{SAOX}$ was free of $\mathrm{Cl}_{2}$ as well as $\mathrm{HgCl}_{2}$ at the beginning of each experiment.

The most important results/calculations are the oxidizer efficiency and the total efficiency of the SAOX. The oxidizer efficiencies indicate very good performance of the SAOX in converting $\mathrm{Hg}(0)$ to $\mathrm{HgCl}_{2}$ in the presence of chlorine. Based on the calculations described above the oxidation efficiency of this SAOX system under these conditions was essentially $100 \%$ for all three experiments. This is comparable but slightly better than what was observed in the Thermo Fisher experiments where the best observed oxidation was $98.3 \%$. The oxidation efficiency of Experiment 3 from the Thermo Fisher experiments was 94.4\%, a slight decrease attributed to increased sample temperature. That decrease was not observed for any of the three experiments performed by WRI. The total oxidation / reduction efficiencies calculated for these experiments were all slightly above $100 \%$, or essentially quantitative. These numbers agree well with what was found by Thermo Fisher in experiments that included a heat trace on the outlets from the $\mathrm{HgCl}_{2}$ converter.

In conclusion, the results of the three experiments presented in this report agree with what was found in Experiment 3 of the Thermo Fisher work. Indeed, the oxidation efficiency is greatly understated when determined using a difference method $\mathrm{Hg}(\mathrm{T})-\mathrm{Hg}(0)$. The SAOX system works very well for the conversion of $\mathrm{Hg}(0)$ to $\mathrm{HgCl}_{2}$ as well as the conversion of $\mathrm{HgCl}_{2}$ back to $\operatorname{Hg}(0)$; both being essentially $100 \%$. The work with this system also supports the assertions that a heat trace is needed between the SAOX and the analyzer to minimize the amount of $\mathrm{HgCl}_{2}$ lost to adsorption.

\section{CONCLUSIONS}

Experimental procedures for conducting the qualification experiments outlined in the August 2007 EPA Interim Traceability Protocol that were developed in a previous study were applied to the Thermo model 81 i elemental calibrators. Calibrator output was evaluated using three concentration settings: 5,15 , and $30 \mu \mathrm{g} / \mathrm{m}^{3}$. Linearity was tested and found to be quite good from $3-30 \mu \mathrm{g} / \mathrm{m}^{3}$. Variables tested included back pressure, ambient pressure, ambient temperature, and line voltage. Each of these variables was tested by using no more than three points. For back pressure, this was no pressure applied, and line restrictions corresponding to 5 psi, and 9 psi back pressure. Umbilicals are not expected to cause greater than 9 psi back pressure. For ambient pressure, output was evaluated at $0.78 \mathrm{~atm}$. (Laramie), $0.95 \mathrm{~atm}$, and 1.1 atm. The Ambient temperatures evaluated were 10,20 , and $30^{\circ} \mathrm{C}$. Line voltages tested were 
105, 115, and 125 volts. For each parameter evaluated, three different conditions were employed. Results for the thermo Fisher model 80i calibrator are summarized below.

1. The elemental mercury output is highly linear.

2. The effect of back pressure that can be encountered due to long stack umbilicals, up to 9 psi, is insignificant.

3. The effect of ambient pressure is insignificant.

4. The effect of ambient temperature can be significant. Components of the calibrators such as Peltier coolers and mass flow controllers can be adversely affected by temperatures ranging from $10-30{ }^{\circ} \mathrm{C}$. Therefore the units should be operated in environments as close to $20^{\circ} \mathrm{C}$ as possible.

5. The effect of line voltage between $105-125 \mathrm{~V}$ is insignificant.

6. Elemental mercury source failures need to better understood, so that designs can be modified or specifications can be provided to minimize such failures. Minimum quality specifications for air and nitrogen quality should be provided.

7. Experimental results with the Thermo stand alone oxidizer unit shows that the SAOX system works very well for the conversion of $\mathrm{Hg}(0)$ to $\mathrm{HgCl}_{2}$ as well as the conversion of $\mathrm{HgCl}_{2}$ back to $\mathrm{Hg}(0)$; both being essentially $100 \%$.

\section{REFERENCES}

EPA, 2007, EPA Traceability Protocol for Qualification and Certification of Elemental Mercury Gas Calibrators, August.

Federal Register, May 18, 2005. EPA 40 CFR Parts 60, 72, and 75. Standards of performance for New and Existing Stationary Sources: Electric Utility Steam Generating Units; Final Rule.

Schabron, J.F., J.F. Rovani, Jr., and S.S. Sorini, 2007, Mercury CEM Calibration, WRI-007R004 topical report to DOE under Cooperative Agreement DE-FC21-98FT40323.

Schabron, J.F., J.F. Rovani, Jr., and M.M. Sanderson, 2008, Mercury CEM Calibration, WRI008-R004 topical report to DOE under Cooperative Agreement DE-FC21-98FT40323. 